\title{
Gambling Market in Croatia: Financial Performance and Fiscal Effect
}

Šimović, Hrvoje; Bajo, Anto; Primorac, Marko; Davidović, Marija; Jelavić, Filip

Source / Izvornik: Fiscus: prudent and responsible public sector financial management,

2019, 4, 1 - 32

Journal article, Published version

Rad u časopisu, Objavljena verzija rada (izdavačev PDF)

https://doi.org/10.3326/efiscus.2019.9

Permanent link / Trajna poveznica: https://urn.nsk.hr/urn:nbn:hr:242:631022

Rights / Prava: Attribution-NonCommercial-NoDerivatives 4.0 International/ImenovanjeNekomercijalno-Bez prerada 4.0 međunarodna

Download date / Datum preuzimanja: 2023-04-26

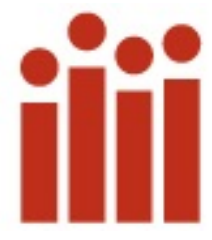

Repository / Repozitorij:

Institute of Public Finance Repository

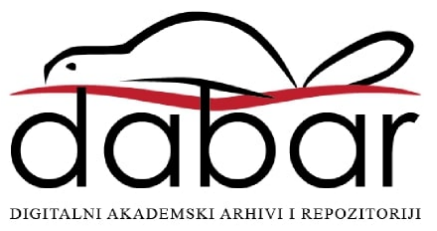



iiii $\begin{gathered}\text { Institute of } \\ \text { Public Finance }\end{gathered}$

No. 9 | November 2019 doi: Io.3326/efiscus.20I9.9 ISSN I849-93I7

\section{FISGUS}

Prudent and responsible public sector financial management

\section{Gambling \\ Market in \\ Groatia: \\ Financial}

Performance

Nind Fiscal Effect

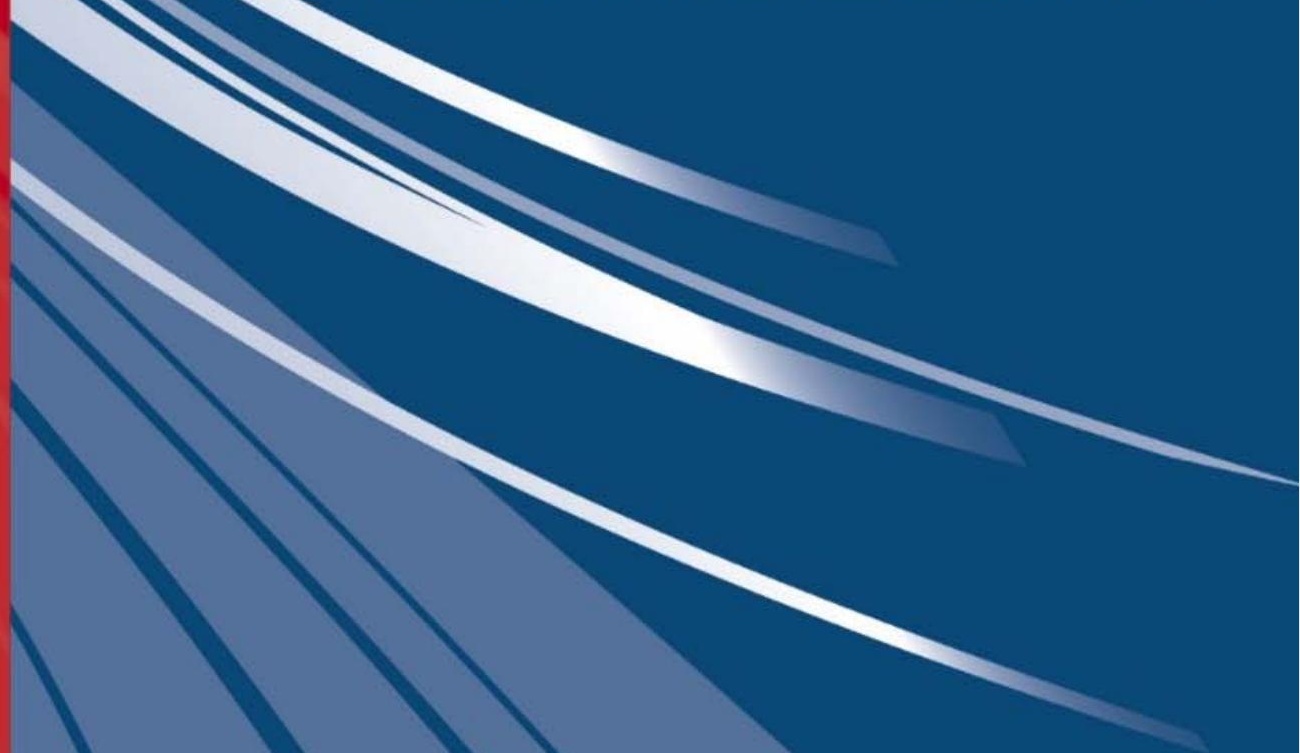





\section{Hrvoje Šimović}

Anto Bajo

Marko Primorac

Marija Davidović

Filip Jelavić

\section{Gambling Market in Croatia: Financial Performance and Fiscal Effect}

The paper analyses the gambling market in Croatia from 2010 to 20I7, i.e. in the period after the effective date of the Act of Games of Chance that is still in force, but only had a couple of amendments. It also includes a detailed analysis of the financial position of the market participants, fiscal effect and contribution of gambling in the state budget revenue.

\section{Introduction}

The gambling market has been gradually liberalised. The former monopolistic position of Croatian Lottery (Hrvatska lutrija - HL), which is a state-owned enterprise, has been impaired in the majority of gambling segments by the appearance of other operators of the gambling games on the market. This has not been the case with the lottery games where HL still has the monopoly. However, the market competition is getting harsher in other gambling segments (betting, slot machine clubs and casinos). The digitalisation strongly contributes to the growth in innovations and offer of all forms of gambling. Thus, in the past couple of years, the players have been attracted to the online betting, live betting, online casinos and online lottery games, either through the offer of such gambling games on the personal computers or smartphones.

Although the digitalisation and the aggressive advertising affect the growth of the gambling demand, the issue of addiction also arises, especially among younger population. Almost every other person older than 15 is involved in some form of lottery, and every third person takes part in prize contests by purchasing specific products or from specific retailers. One quarter of the population takes part in prize contests organised by printed media, and every seventh person bets (Zoričić, Torre i Orešković, 2009; Bodor et al., 2OI8).

The main goal of this paper is to analyse the gambling market in Croatia and assess the financial position of the main market participants. By reviewing the literature, it can be concluded that no such analysis has been done for Croatia so far. On the other hand, there are analyses of the regulatory framework of this circumstance (Anić and Vouk, 2000; Torre, Zoričić and Škifić, 
20IO; Horak, Dumančić and Pošćić, 2017), as well as of the addiction issues that are a consequence of betting and gaming (Zoričić, Torre and Orešković, 2009). Besides the analysis of the financial position, the paper also analyses the fiscal effect of the gambling sector on the budget revenue and assesses the current legal framework for the regulation of gambling in Croatia.

\section{Regulation of Gambling}

Gambling games have always been an inevitable companion of the social and individual life. The players are usually thrilled to be able to participate in them and they are ready to pay a high price, not only in money, but in their time as well. Furthermore, they are ready to assume both the physical and mental risk related to gambling, since betting and gambling may cause addiction. Therefore, it is very important to effectuate the appropriate legislation to regulate the organisation of gambling and prevent criminal activities. Similar problems are also caused by other vices, such as alcohol and tobacco products, which, due to the addiction problems they cause, have a relatively stable demand and are subject to the special sales taxes imposed by the government in order to generate additional budgetary resources.

Regulation of gambling in the European Union

Organisation of gambling, especially gaming and betting, is prohibited or, more often, government-controlled by means of licences, in the majority of countries in the world. The regulation of gambling in the European Union (EU) differentiates largely among the member countries. In some countries, gambling is a matter of market relations (e.g. Austria and United Kingdom), whereas the Nordic countries insist on maintaining the state monopoly (Torre, Zoričić and Škifić, 2OIO).

There are still no guidelines for organisation of gambling on the EU common market. All EU members organise gambling in accordance with their respective regulations, with due regard for the principles of equality of all operators who are interested in organisation of gambling and who meet the requirements set out by the current regulations of a particular member country (Horak, Dumančić and Pošćić, 20I7).

\section{Regulation of gambling in Croatia}

The gambling in Croatia has been regulated by the Act of Games of Chance (OG 87/O9, 35/I3, I58/I3, 4I/I4, I43/I4, hereinafter: The Act) that defines the types of gambling, the rights to organise gambling and methods in which the government can impact the business operation of the gambling operators.

The right to organise gambling games falls under the exclusive competence of the Government of the Republic of Croatia. However, by means of a special decision and at the suggestion of the Ministry of Finance, this right can be transferred to companies and non-profit organisations. The operators must be headquartered in Croatia. It has already been mentioned in the intro that, when it comes to lottery, HL still has the monopoly, whereas the other segments of gambling - betting, slot machine clubs and casinos - have been liberalised to a certain extent. Besides the required business licence, there is also a special decision laid down by the Government that specifies the maximum number of companies that are given the approval to organise betting as well as to open slot machine clubs and casinos (Decision on Granting the Right to Organise Gambling for Each Individual Gambling Category, OG II6/I8).

Besides the required business licences, the Government also lays down a set of specific rules and restrictions which the operators are obligated to comply with. There is a number of ordinances (see the references for details) which the Government uses as supplements to the 
Act, that is for a more precise regulation of gambling, remote betting, online casinos, minimum spatial and technical requirements for organisation of gambling at casinos and slot machine clubs as well as betting shops.

A significant portion of the operators' revenue is going to the state budget. The Act stipulates not only the tax on winnings from gambling, but also fees (annual and monthly) paid by the operators. It also defines programmes financed by the revenue generated from the gambling activities. For instance, a part of this money is used for financing the organisations that contribute to fighting any form of addiction, promote sports, or that are engaged in social and charity activities, in meeting the needs of impaired people, that focus on culture and technical culture and contribute to the development of the civil society. The Government allocates 50\% of the fees collected in connection with the organisation of gambling activities for financing of the above-mentioned programmes.

\section{Gambling Market in Croatia}

The gambling market includes companies registered for gaming and betting activities (NKD 9.2000) according to the national economic activity classification (NKD). However, a part of the companies registered for organisation of gambling activities is also registered in other NKD categories, e.g. as hotels and similar facilities, production of games and toys, non-specialised wholesale and other entertainment and recreation activities etc., which is in particular the case when it comes to the casino activities. This fact aggravates the analysis, so the focus is only on the companies registered for gaming and betting activities (NKD 9.2O00).

The main sector indicators: revenue, number of companies, employment and profitability In the period $2008-2017$, the gaming and betting sector recorded a decrease in the number of companies, i.e. an increase in the market concentration (graph I), which was mainly a result of mergers and acquisitions, especially in 2013 and 20I6. In 20I3, Admiral International Kasinos was merged with Captura, Osmica was merged with International Evona, and ABCAstoria was merged with Prva sportska kladionica (PSK). The similar scenario repeated in 2016, which was a year of a few mergers - Hattrick was merged with PSK, Tempo-Star was merged with Germania Sport, whereas Captura, Bolus and Blue Sky were merged with Interigre. These mergers mostly included affiliated companies in the way that the owners of several subsidiary companies merged such companies into a single one.

Despite the drop in number of companies in this sector, a significant revenue increase was recorded, which in 2017 amounted to more than HRK 3 billion. Furthermore, due to the concentration increase in the sector, almost $70 \%$ of the revenue generated in this segment in $20 I 7$ referred to the five largest companies in terms of their generated turnover (Super Sport, HL, Interigre, Hattrick-PSK and International Evona), which represents a significant increase compared to 2009 when the revenue amounted only $52 \%$. 
Graph I Sector revenue (in HRK million), number of companies and share of the five largest companies

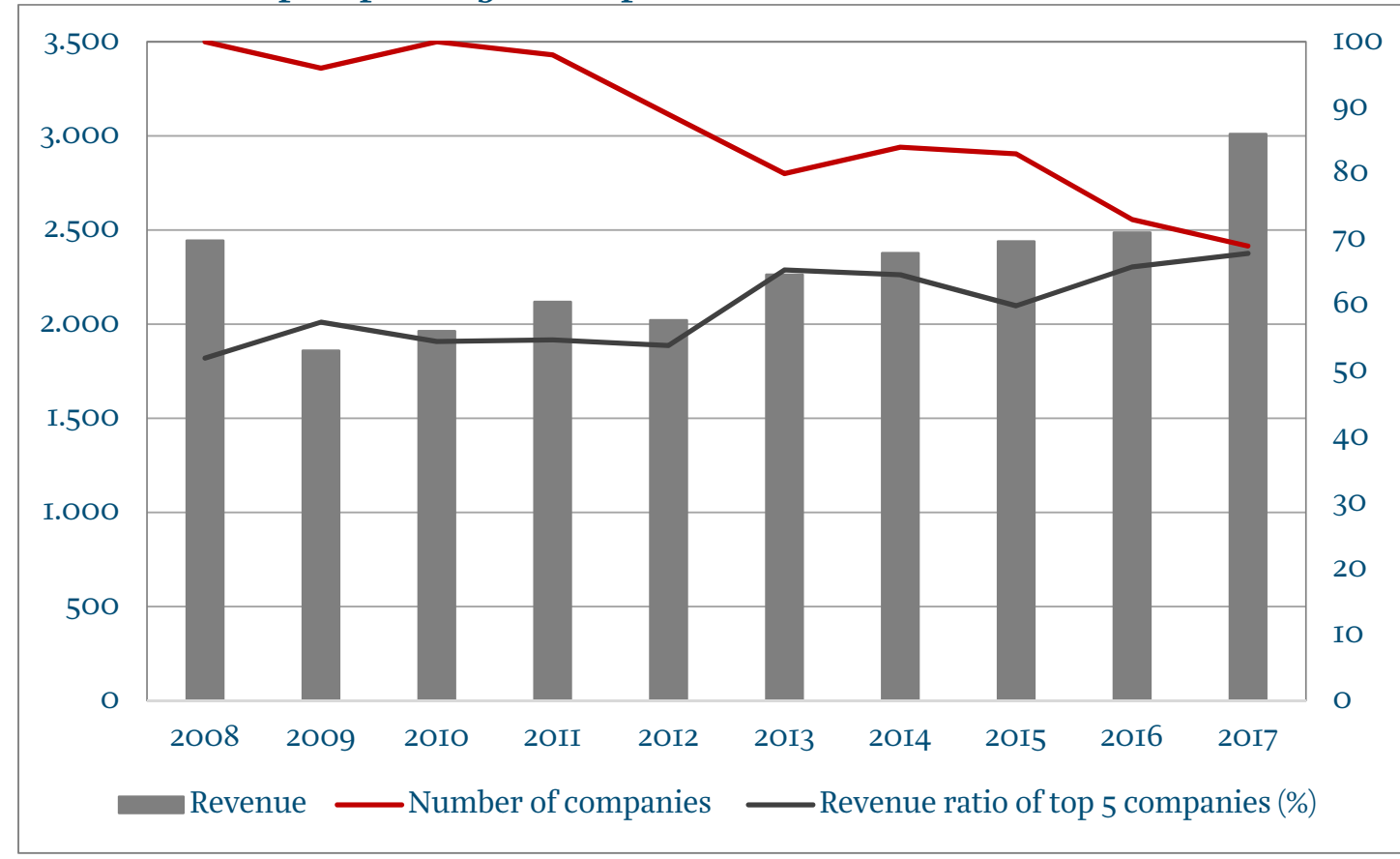

Source:

the graphical record produced by the author based on the data provided by FINA

\section{Graph 2 Structure of the overall sector turnover per} biggest companies in 2017 (in \%)
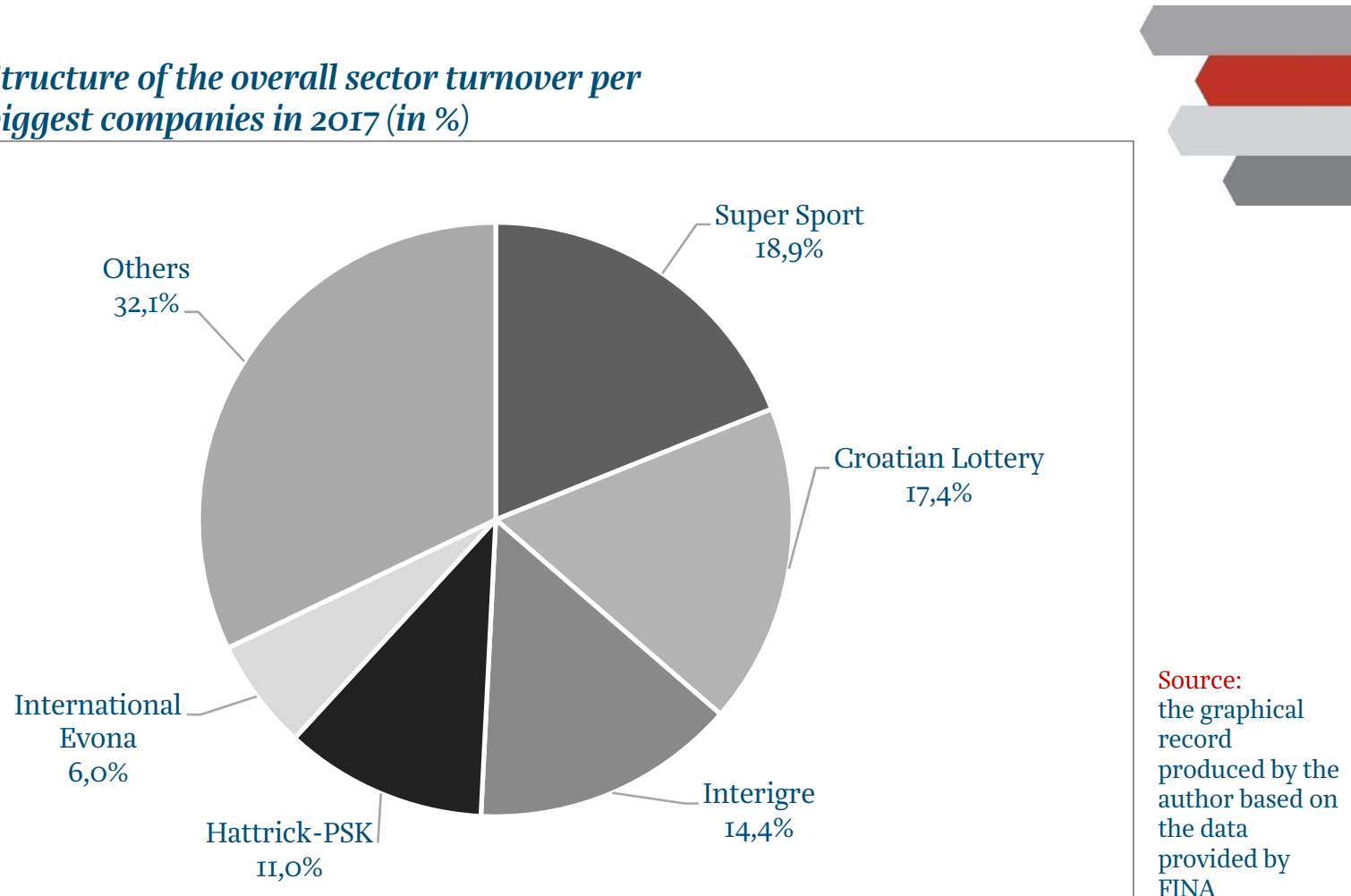

An upturn in profit on the sector level was higher than the revenue growth, which brought the net margin of the sector to approximately I5\% (graph 3). The sector profit was largely determined by the results of the bookmakers, in particular, Super Sport and Hattrick-PSK, and in the last couple of years, HL as well. The Super Sport profit of HRK 292 million in 2017 made $63 \%$ of the sector profit (together with Hattrick-PSK and HL it is more than 90\%). 


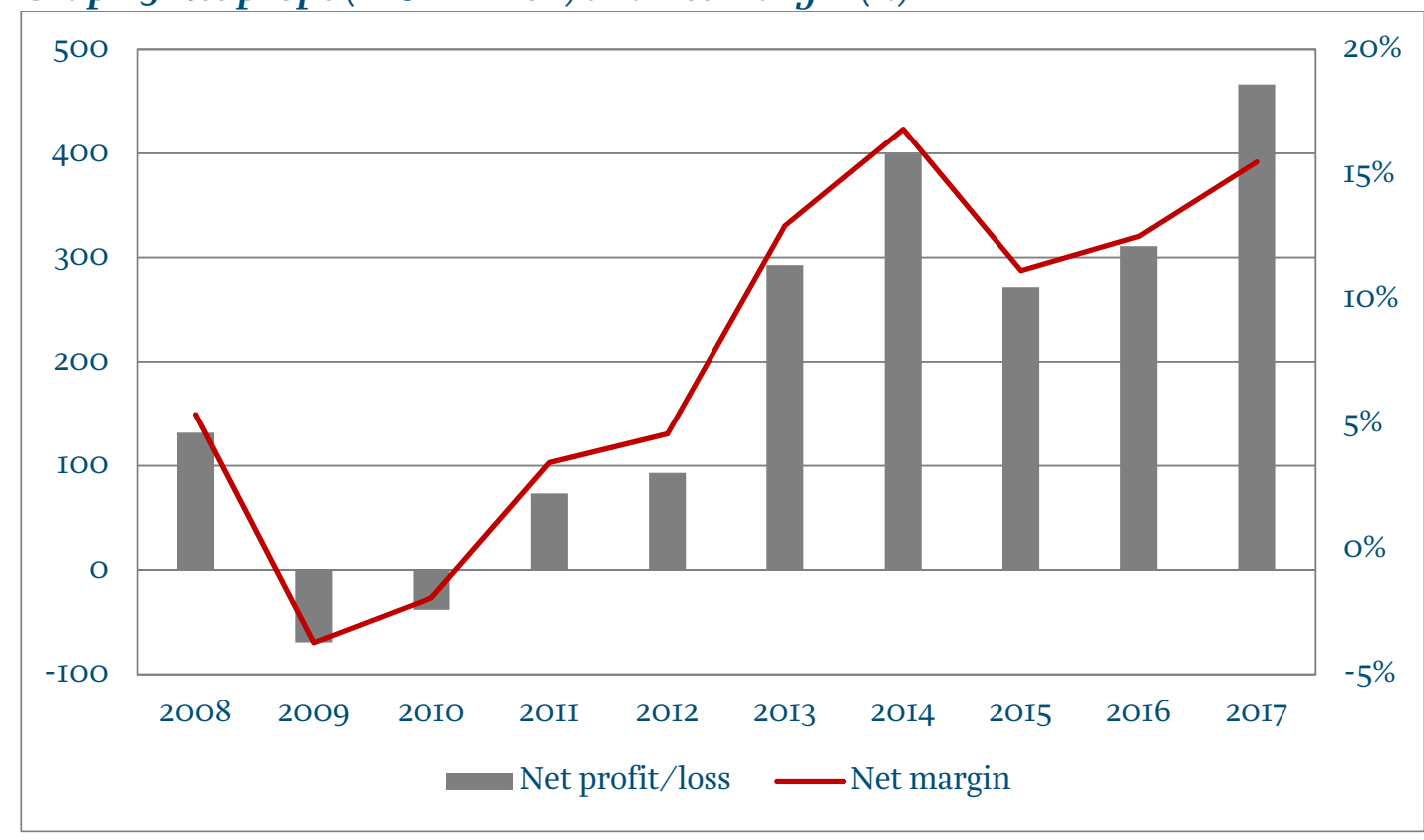

Source: the graphical record produced by the author based on the data provided by FINA

Regardless of the overall results that are satisfactory, there are large differences in profitability among the companies. Graph 4 points out to a constant presence of a relative share of lossgenerating companies in the sector of about $40 \%$, despite the profit increase on the sector level. Besides, despite the satisfactory results of the entire sector, no significant inflow of new competitors was recorded. In the past two years only five new companies have joined the sector, whereas in the same period ig companies left it.

\section{Graph 4 Profit-generating vs loss-generating companies (in \%)}
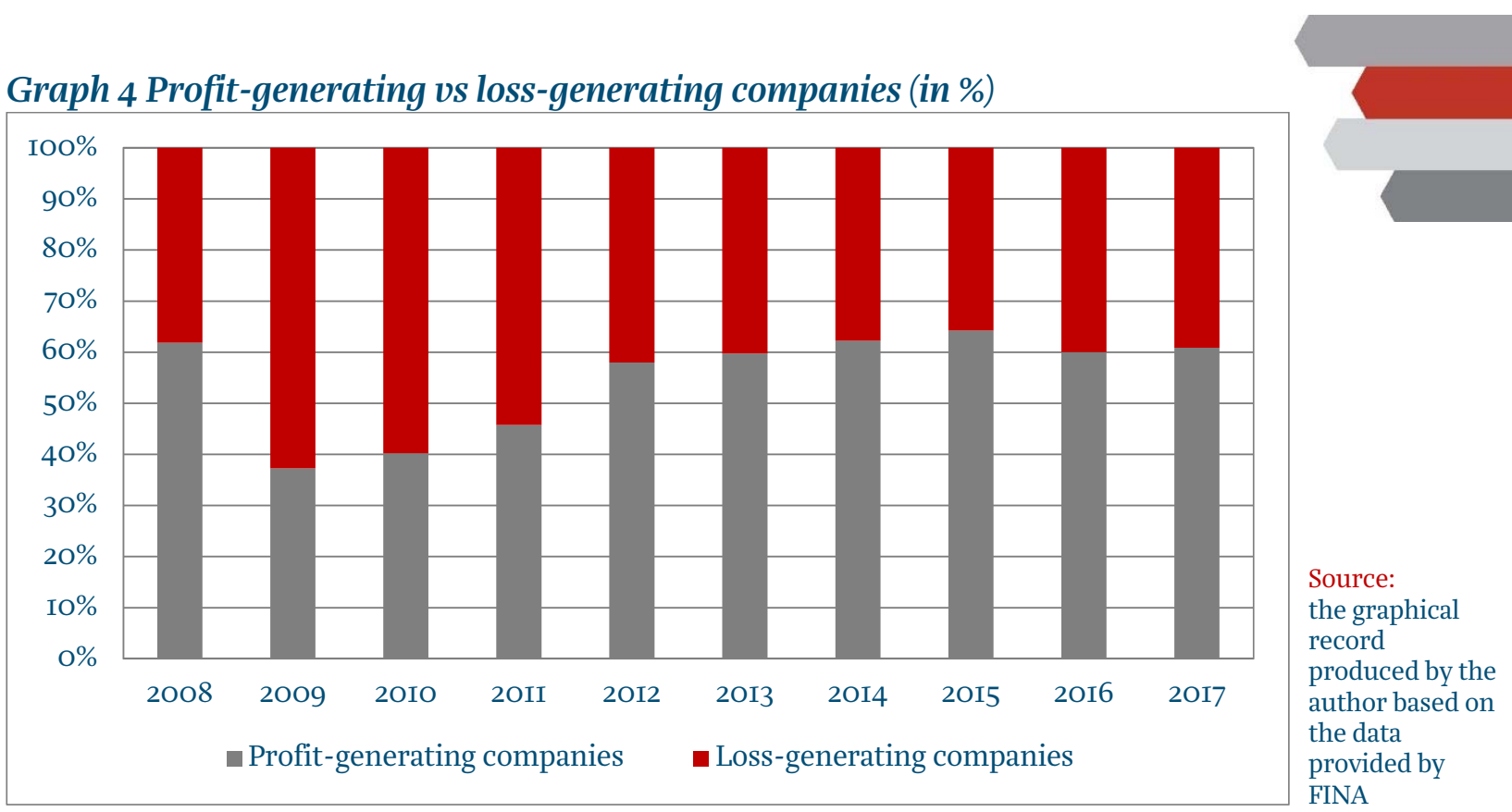

At the end of 20I7, the gaming and betting sector employed 6,300 people, which was 500 less than in 20IO, but I,OOO more compared to 20I5. The headcount mostly did not follow the revenue growth in the last five years, so that the headcount productivity also grew (graph 6). The revenue per employee in 2010 amounted to HRK 28I,OOO and HRK 504,00O in 20I7, which 
represented a growth of $80 \%$. Such labour productivity growth can be hardly observed in other segments, which made this activity particularly attractive for investments.

\section{Graph 5 Employment (HRK ooo) and personnel cost (\%)}

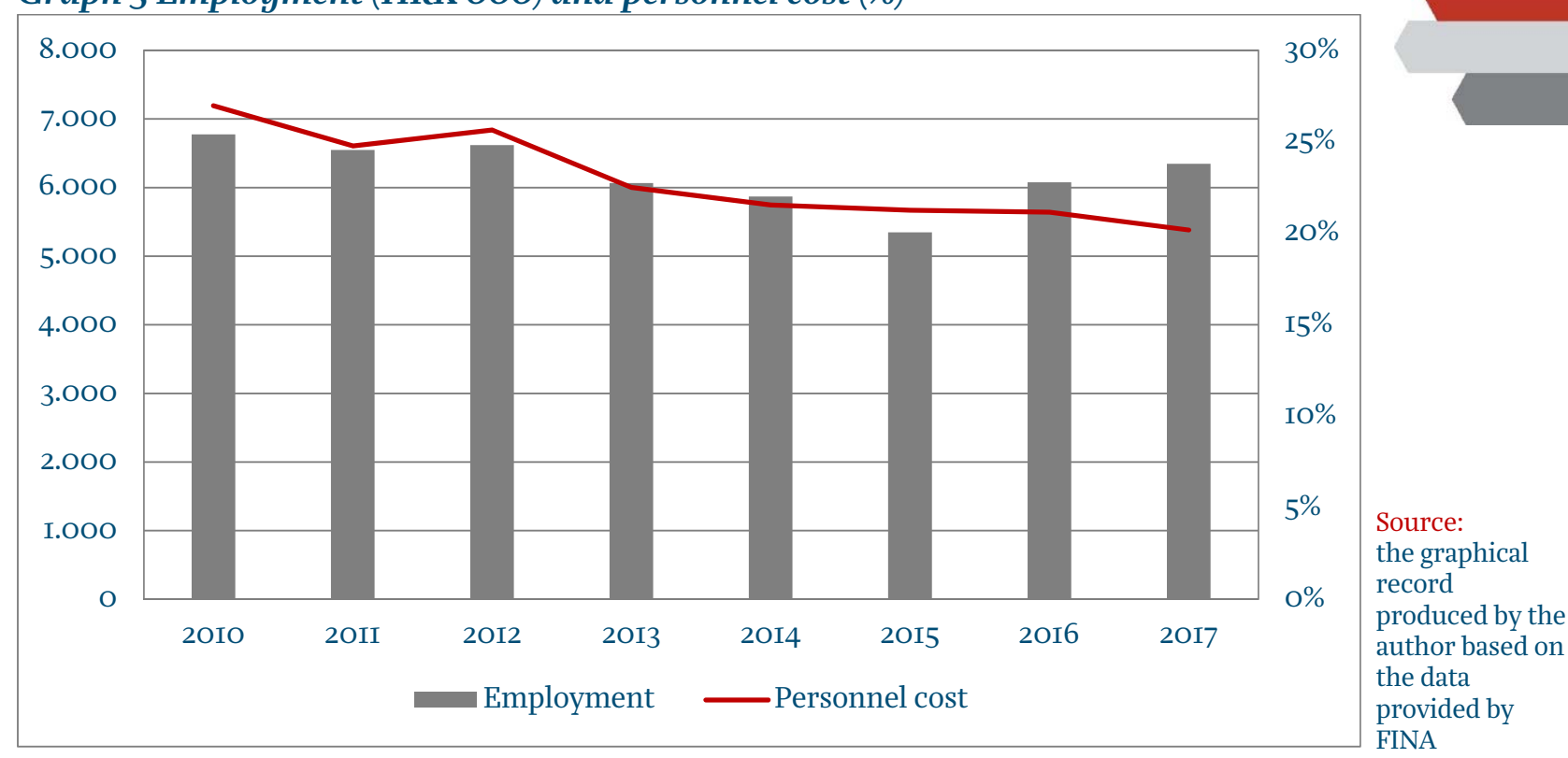

Graph 6 shows that the average gross annual salary (personnel cost per employee) grew slower than the revenue per employee, which resulted in higher revenue of the sector. Although the headcount in 2017 was almost I8\% lower than in 20IO, the total wage bill was higher by 30\%, showing the salary growth which amounted to $2 \%$ per year on average during the reference period. Other costs grew significantly faster than the personnel cost.

Graph 6 Revenue and personnel cost (HRK ooo)
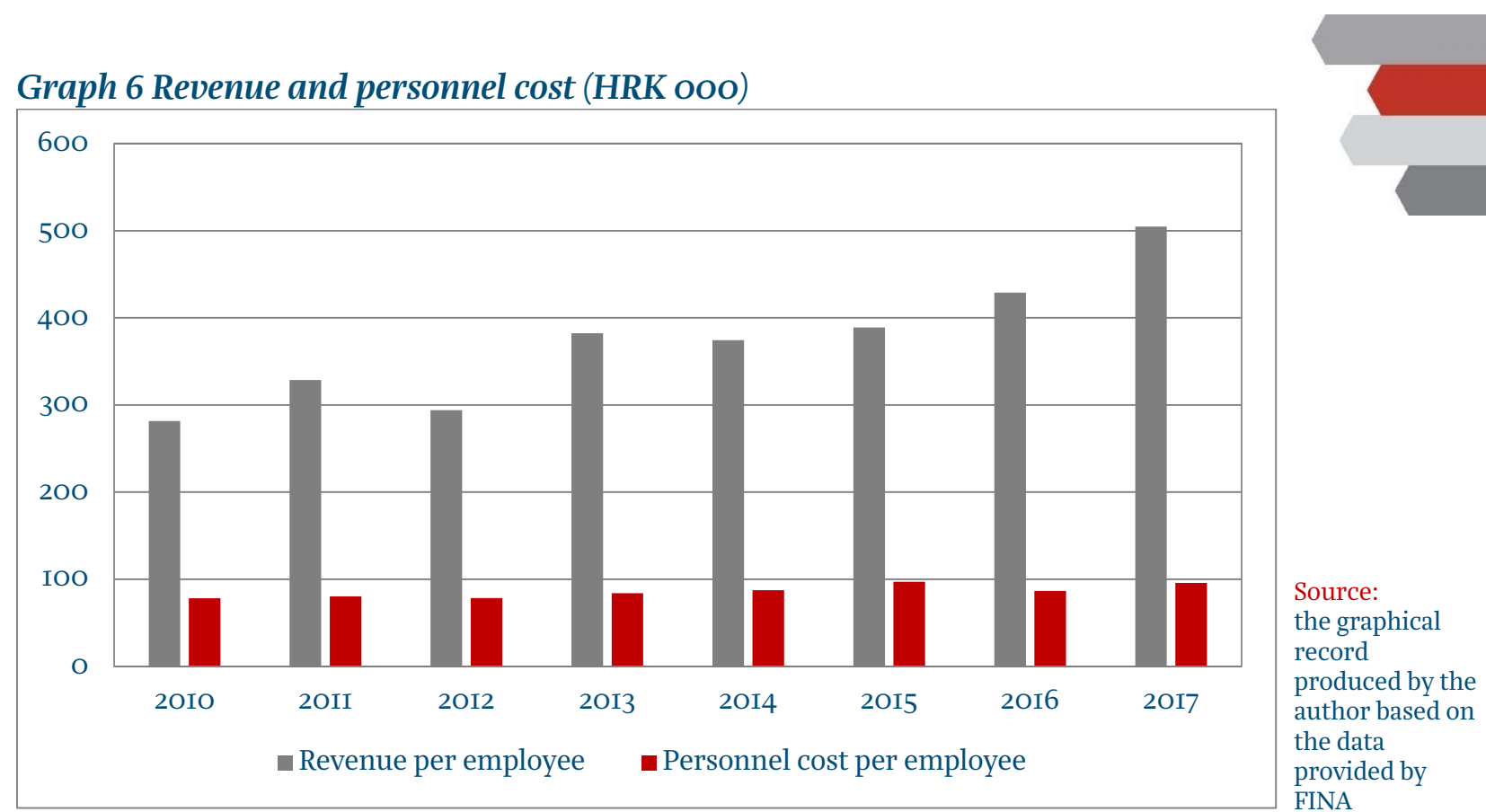


\section{Financial indicators}

The liquidity of the sector and the indicator of financial stability significantly increased in the observed period (table I). In 20I7, the cash ratio was significantly higher than its critical value of 0.5 , the accelerated liquidity ratio was significantly higher than its critical value of $\mathrm{I}$, and the financial stability ratio was significantly below I, which was its critical value.

\section{Table I Liquidity and Financial Stability Indicators}

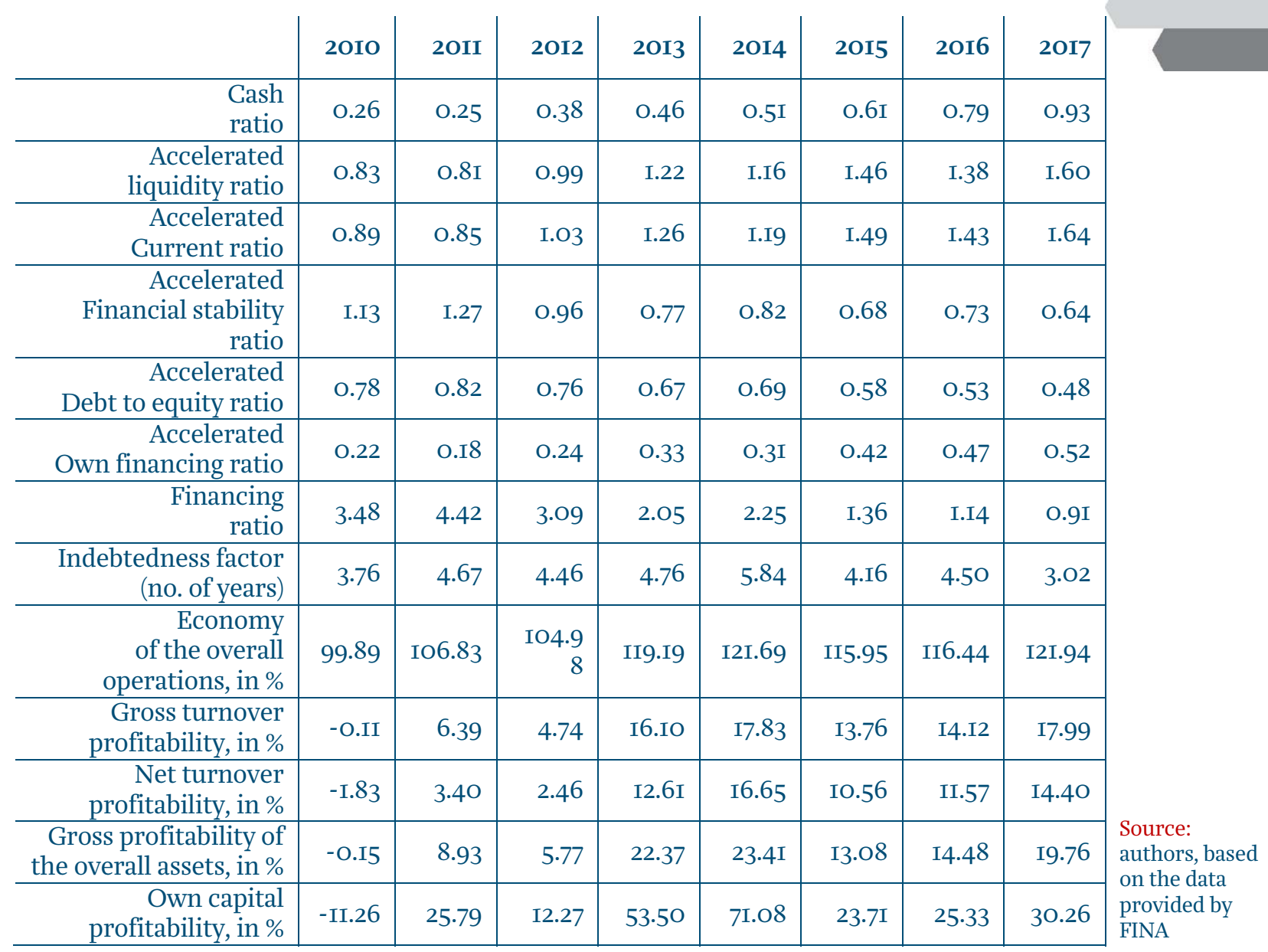

Over the years, the increase in profitability in gaming and betting sector significantly improved indebtedness. Since 20I3, the range of the debt ratio has been acceptable. The own financing ratio grew above $50 \%$ in 2017 and the financing ratio went down below the critical value of $\mathrm{I}$ in the same year. During the most of the observed period, the indebtedness factor was below the critical value of 5, except in 20I4. The profitability indicators point out to significant returns that were achieved in these segments, but with a highlighted volatility (table 3). The latest data show a satisfactory return on assets higher than $15 \%$ and a return on own capital of $30 \%$ in 2017 .

\section{Market Analysis According to the Types of Gambling}

The overall gaming and betting sector can be observed from the perspective of gambling categories, which include lottery games, casinos, slot machine clubs and bookmaking. The analysis is exacerbated by the fact that certain companies, especially the larger ones, have a scope of several activities. Considering the market concentration, the four main businesses 
(Super Sport, HL, Interigre and Hattrick-PSK) make more than $60 \%$ of the market. Each of them is a leader in their own segment of the gambling market (graph 7).
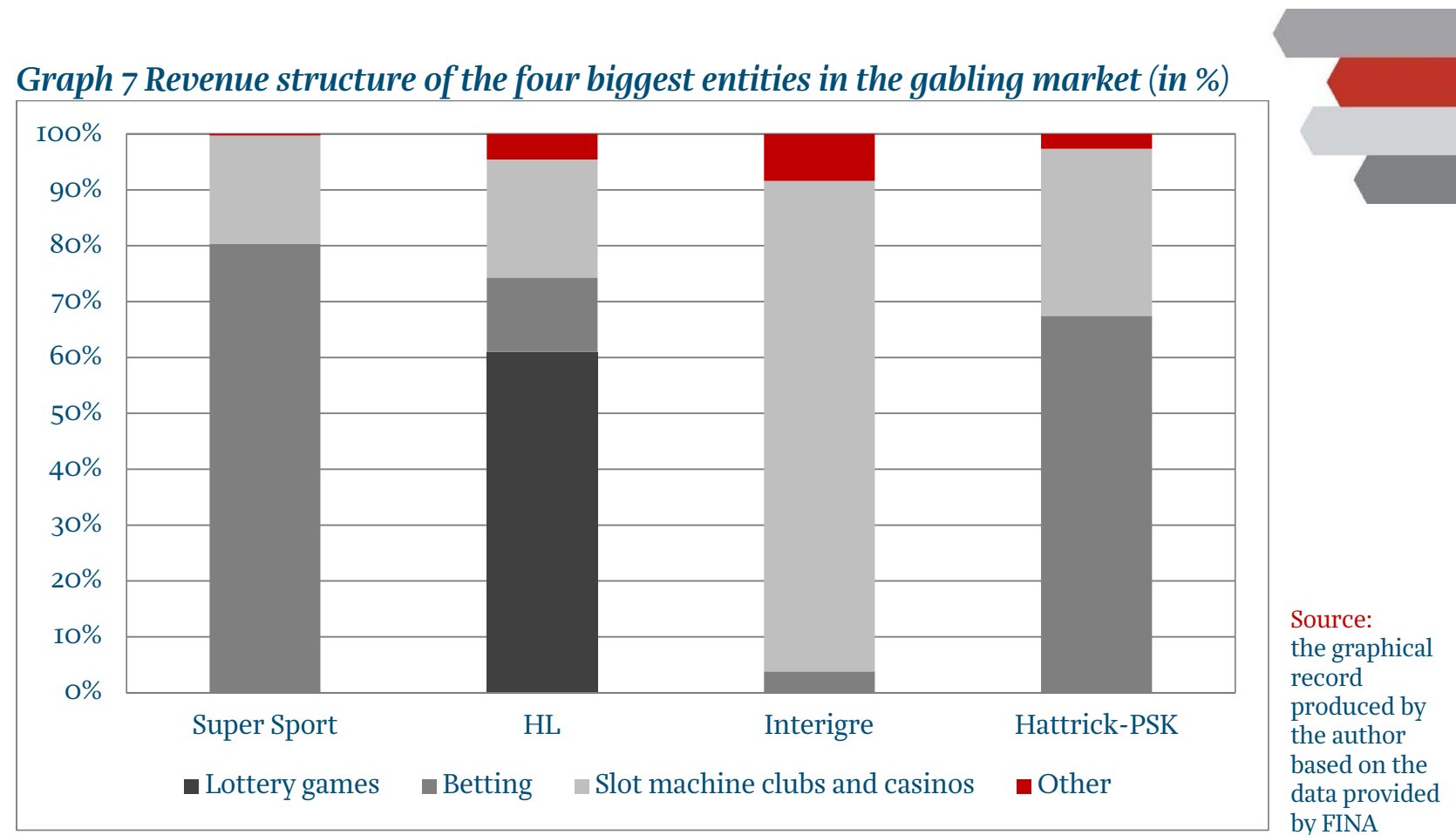

HL has the exclusive right to organise lottery games, but it also present in other three segments. Bookmakers, being the biggest generator of the sector profitability also operate in the segment of slot machines and casinos. Due to the concentration of revenue and profit, as well as overlapping between the market segments, the bigger companies have been classified into segments that are most appropriate for them in term of the revenues structure. Although HL is present in all four segment, this company generates the majority of their revenue through lottery games. Therefore, HL is observed separately. Super Sport and Hattrick-PSK generate the majority of their revenue through betting shops, which is why they are classified in this category, despite the fact that they are also active in the segment of casinos. Interigre generates the majority of their revenue through slot machine clubs and casinos. Although, according to their direct revenue from casinos, Super Sport and HL occupy the first two positions, generating HRK IIO million and HRK 80 million respectively, they are excluded from the analysis of the casino indicators because it is impossible to separated that result from the results of other activities of these two companies.

Besides the aggregate sector indicators obtained by the absolute sum of all results of all companies, median indicators will also occasionally be presented so that we could include companies that would otherwise provide a negligible contribution to the sector indicator. Since all sectors have a rather high concentration, the indicators based on the cumulative values are mostly set by the largest companies.

\section{Hrvatska lutrija and lottery games}

Because of the monopolistic position of HL in the sector of lottery games, HL was the only company subject to the analysis. HL revenues made about $17 \%$ of revenue generated from gaming and betting, but with the employment of about I8\%, its profit contribution was only about IO\%. 
Table 2 HL results and comparison with other activities in 2017

\begin{tabular}{|c|c|c|c|c|c|c|}
\hline HRK (million) & Revenue & Employed & EBITDA & EBIT & $\begin{array}{r}\text { Net } \\
\text { profit }\end{array}$ & \multirow{7}{*}{$\begin{array}{l}\text { Source: } \\
\text { authors, based } \\
\text { on the data } \\
\text { provided by } \\
\text { FINA }\end{array}$} \\
\hline $\mathrm{HL}$ & 525 & $\mathrm{I}, 2 \mathrm{I} 4$ & $8 \mathrm{I}$ & 56 & 45 & \\
\hline Casinos & 297 & 871 & 8 & -42 & $-4 I$ & \\
\hline Slot machine clubs & I,392 & 2,473 & 279 & II9 & 96 & \\
\hline Betting & $\mathrm{I}, 467$ & 3,152 & 554 & 464 & 378 & \\
\hline $\begin{array}{r}\text { Gaming and betting } \\
\text { sector total }\end{array}$ & 3,156 & 6,578 & 837 & 591 & 475 & \\
\hline $\begin{array}{l}\text { Share of HL in the overall } \\
\text { gaming and betting (\%) }\end{array}$ & I7 & I8 & IO & 9 & IO & \\
\hline
\end{tabular}

In the period 2010 - 2017 the average revenue growth rate of HL amounted to a modest I\% per year, which was below the industry average (about 9\%). The results of the core lottery business was even worse than that, but it was partially compensate by new sectors such as casinos and betting. The weak revenue growth was the result of the HL's lack of initiative to enter other gambling sectors, which is why the company is not the "key player" on the market.

Regardless of the monopoly in the lottery sector, in the last couple of years HL has intensively tried to enter other market sectors such as betting, machine slots and casinos (graph 8). It is possible to expect that HL would in the future maintain their position as one of the leaders on the gambling market.

\section{Graph 8 Change of the HL's revenue structure} (comparison of 2010 and 2017 revenue structure, in \%)

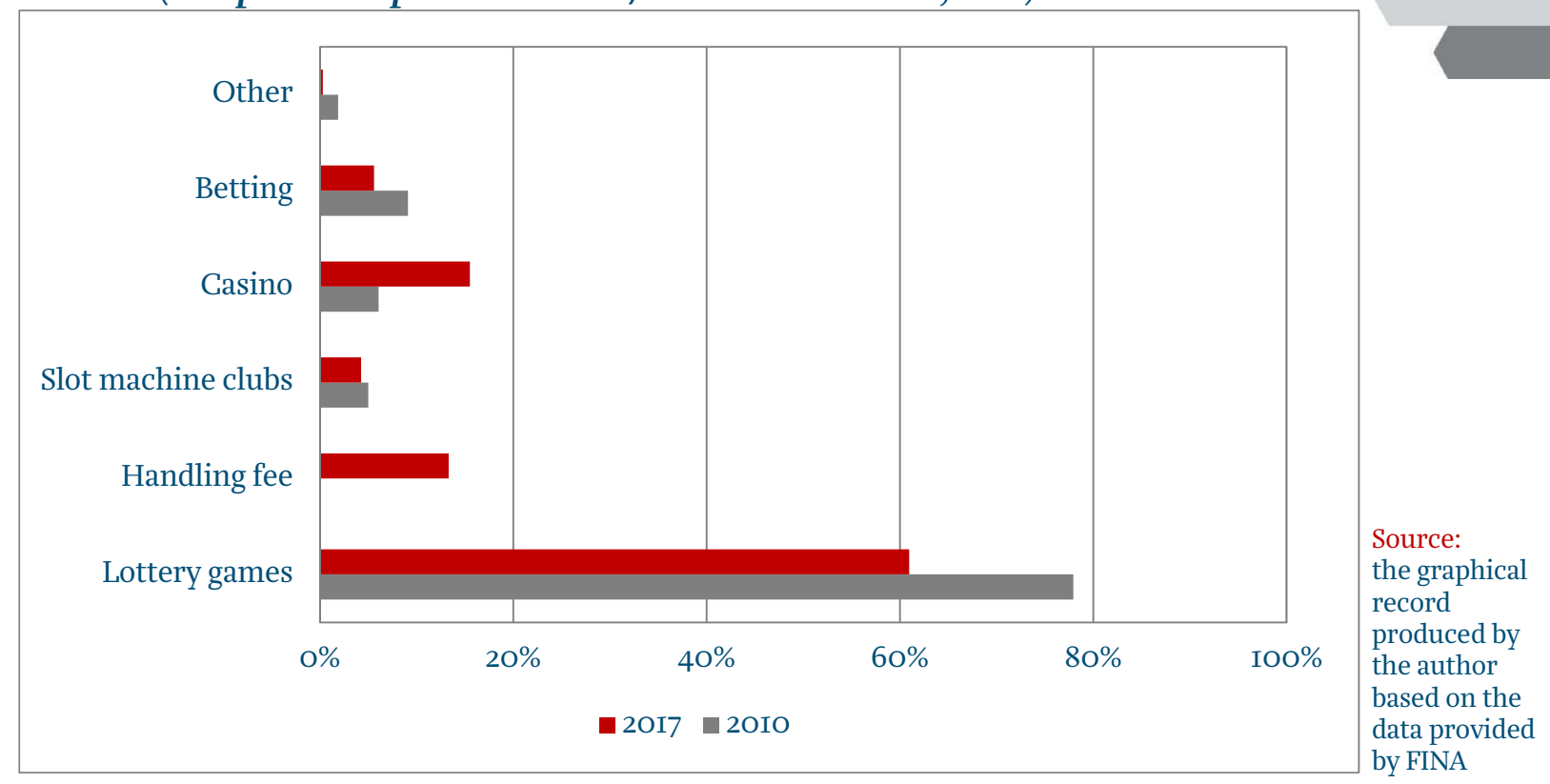

When it comes to the profitability of HL, it was below the profitability of the betting sector, and when it comes to EBITDA margin of HL, it was below the EBITDA margin of casinos and slot machine clubs (see table 3). HL managed to catch up with an overtake the result of the casinos and slot machine clubs since it is a less capital intensive company spared of debts and depreciation. 
Table 3 HL profitability and comparison with other sectors in 2017 (in \%)

\begin{tabular}{|c|c|c|c|c|c|c|}
\hline Margins & EBITDA & EBIT & Net & ROE & ROGE & \\
\hline HL d.o.o. & I5 & II & 9 & 49 & 47 & \\
\hline Casinos (median) & I8 & II & 3 & 8 & 6 & \\
\hline Slot machine clubs & 20 & 9 & 7 & 17 & II & \\
\hline Betting & 38 & 32 & 26 & 40 & $3 \mathrm{I}$ & \\
\hline $\begin{array}{r}\text { Gaming and betting } \\
\text { sector total }\end{array}$ & 27 & I9 & I5 & 30 & 22 & $\begin{array}{l}\text { Source: } \\
\text { authors, based on the data } \\
\text { provided by FINA }\end{array}$ \\
\hline
\end{tabular}

Graph 9 shows that the overall employment in HL since 20IO was rather stable. The cost per employee was on average by $20 \%$ higher than the sector average (graph IO). In 20I7, the average cost per employee in HL amounted to about HRK II5,OOO, whereas the average cost per employee on the sector level amounted to HRK 95,000.

\section{Graph 9 HL employment and personnel cost(HRK ooo)}

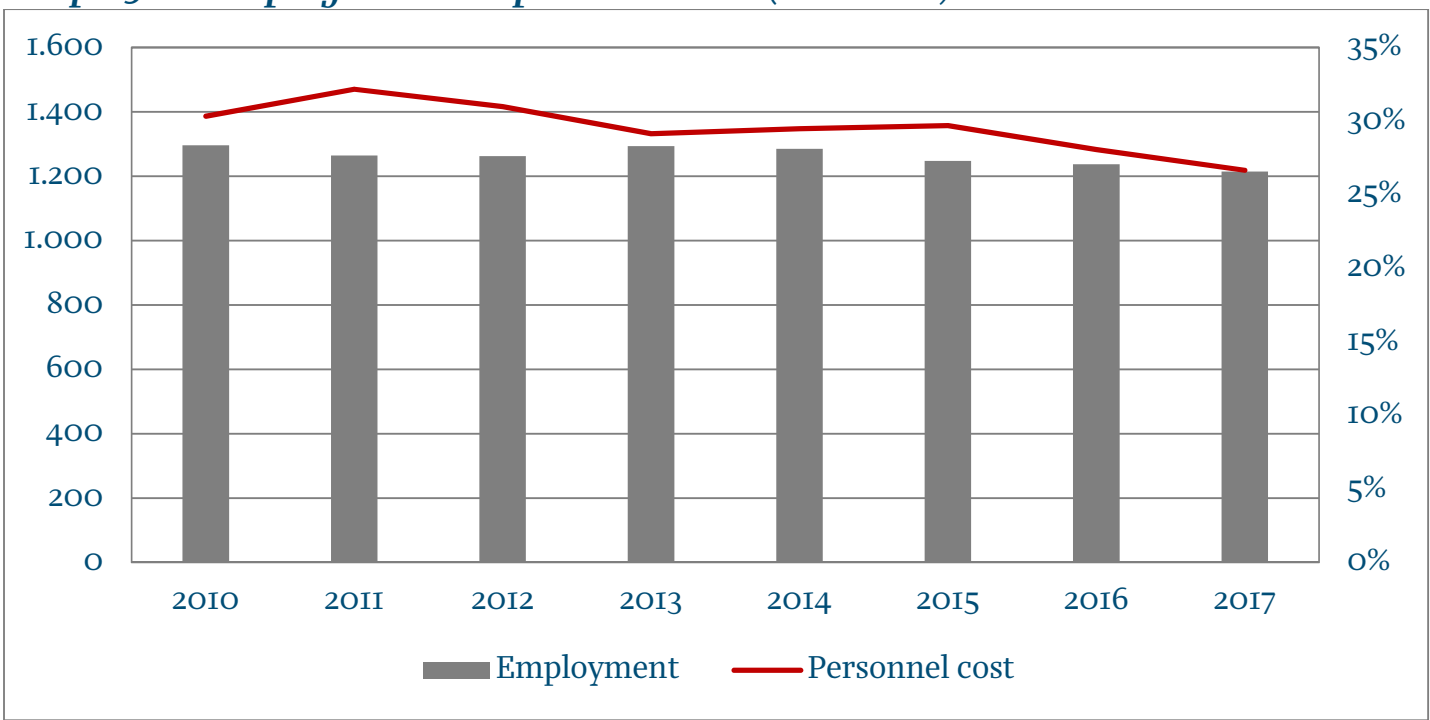

\section{Graph Io HL revenue and personnel cost (HRK ooo)}

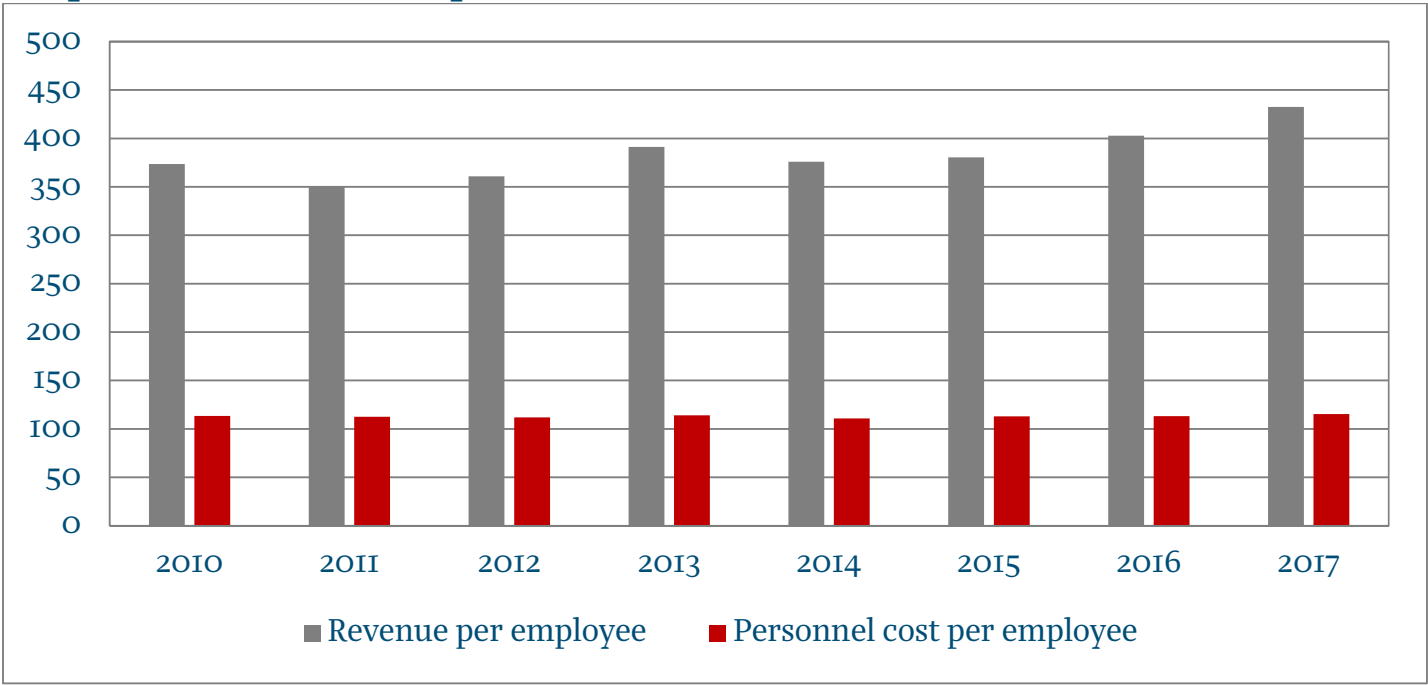

Source:

the graphical record produced by the author based on the data provided by FINA
Source:

the graphical record produced by the author based on the data provided by FINA 
In 20I7, the net margin amounted to $9 \%$, and the profitability growth is shown in graphs II and I2.

\section{Graph II HL net profit (HRK million) and net margin (\%)}

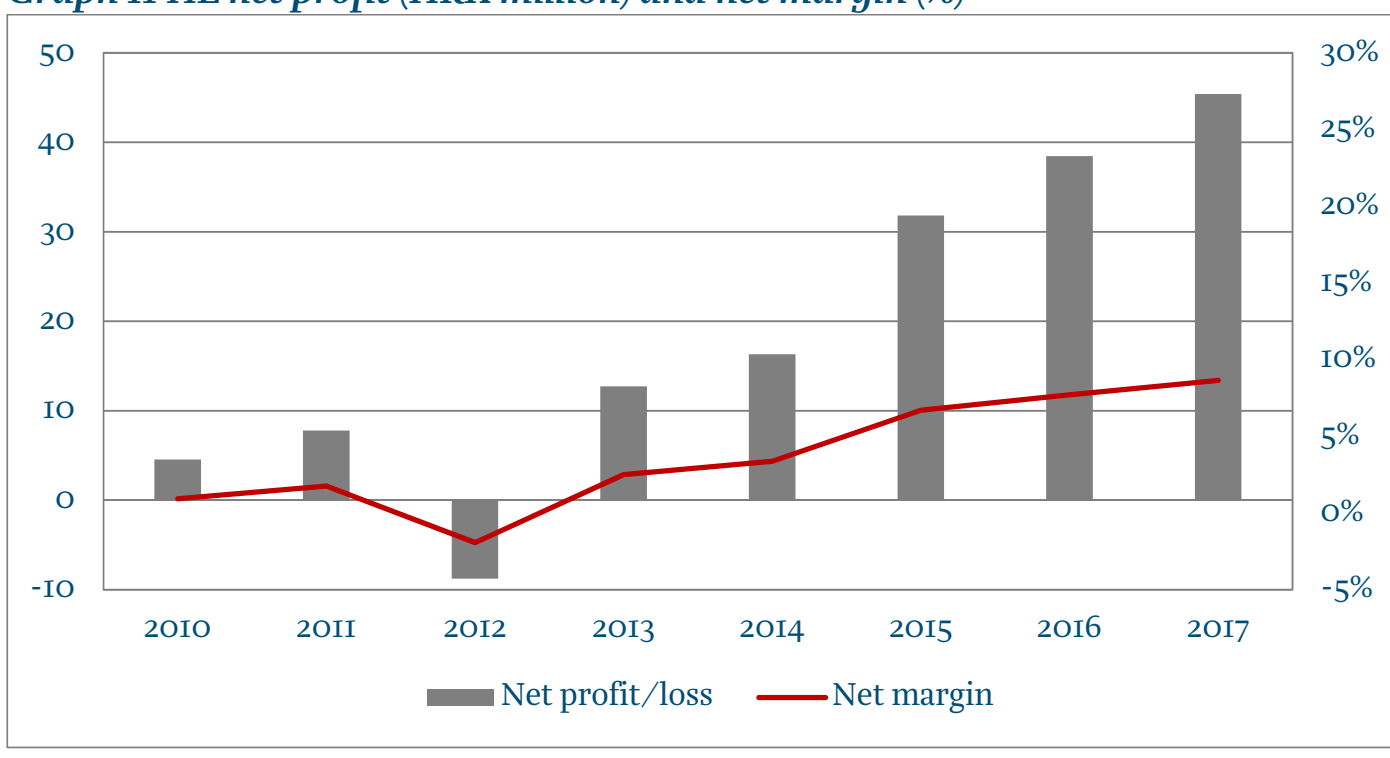

\section{Graph 12 Profitability of HL}

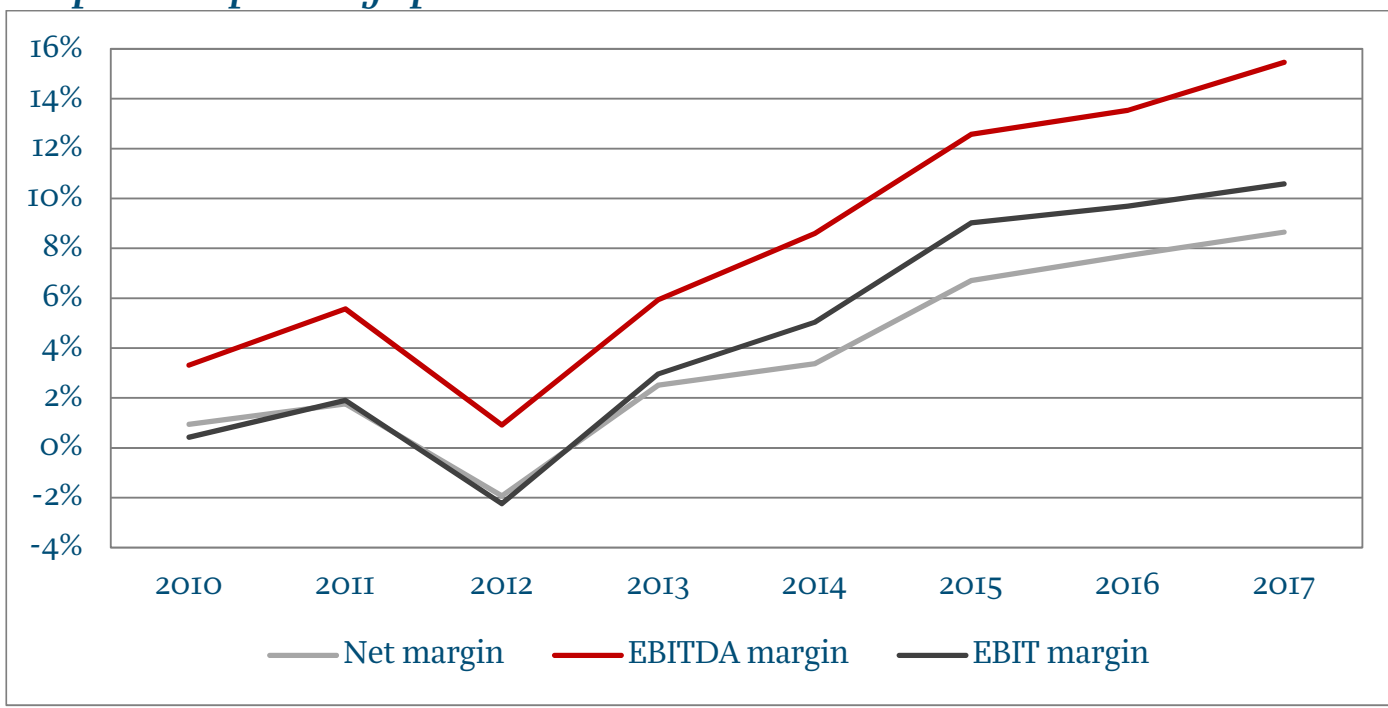

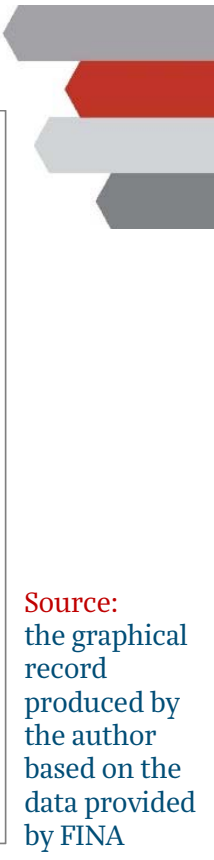

Source:

the graphical record produced by the author based on the data provided by FINA

The liquidity and indebtedness of HL were slightly below the gaming and betting sector average (graph 13). The liabilities mostly referred to liabilities to lottery winners paid during a longer time period. In the gaming and betting sector it is important to allocate a portion of the liquidity for possible prize payouts to winners. Therefore, a portion of funds may be treated as operating capital and not only as liquidity surplus. 
Graph 13 Current liquidity and indebtedness in HL

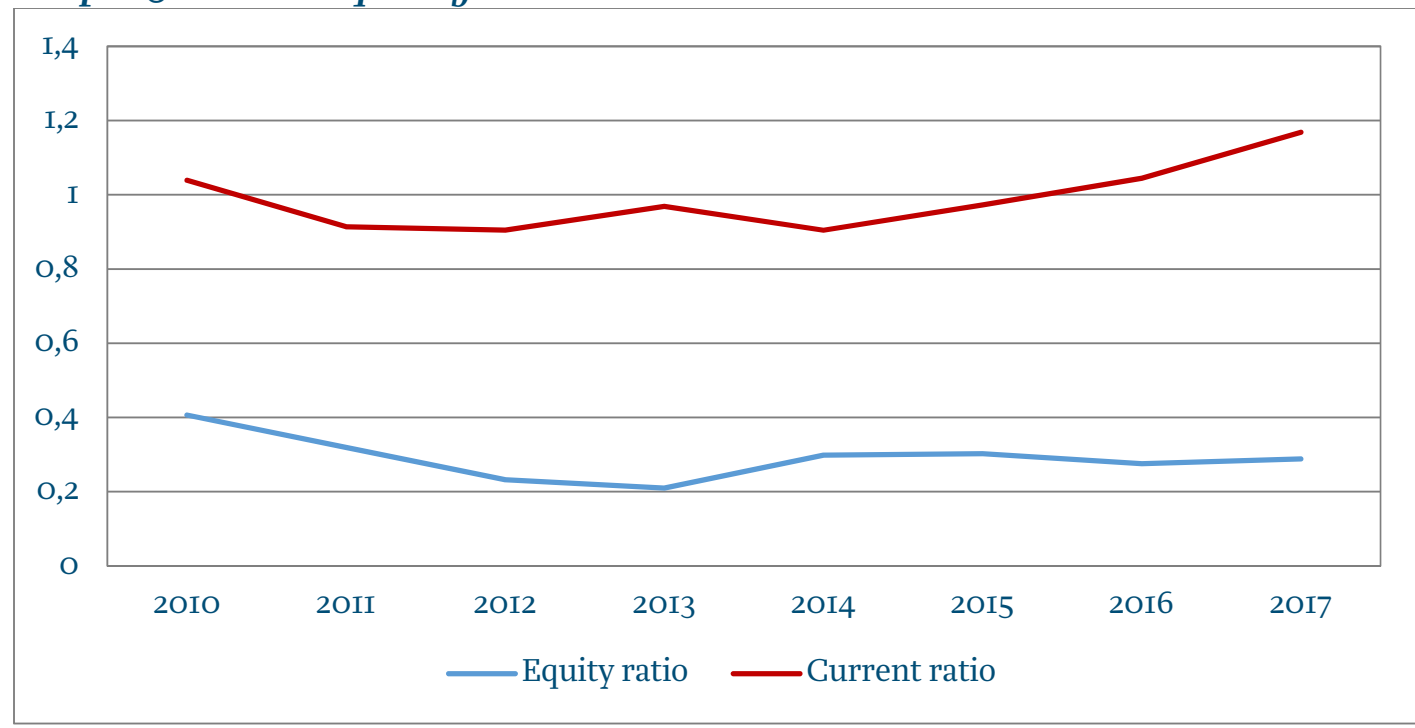

Source:

the graphical record produced by the author based on the data provided by FINA

\section{Graph I4 HL net debt and EBITDA (HRK million)}

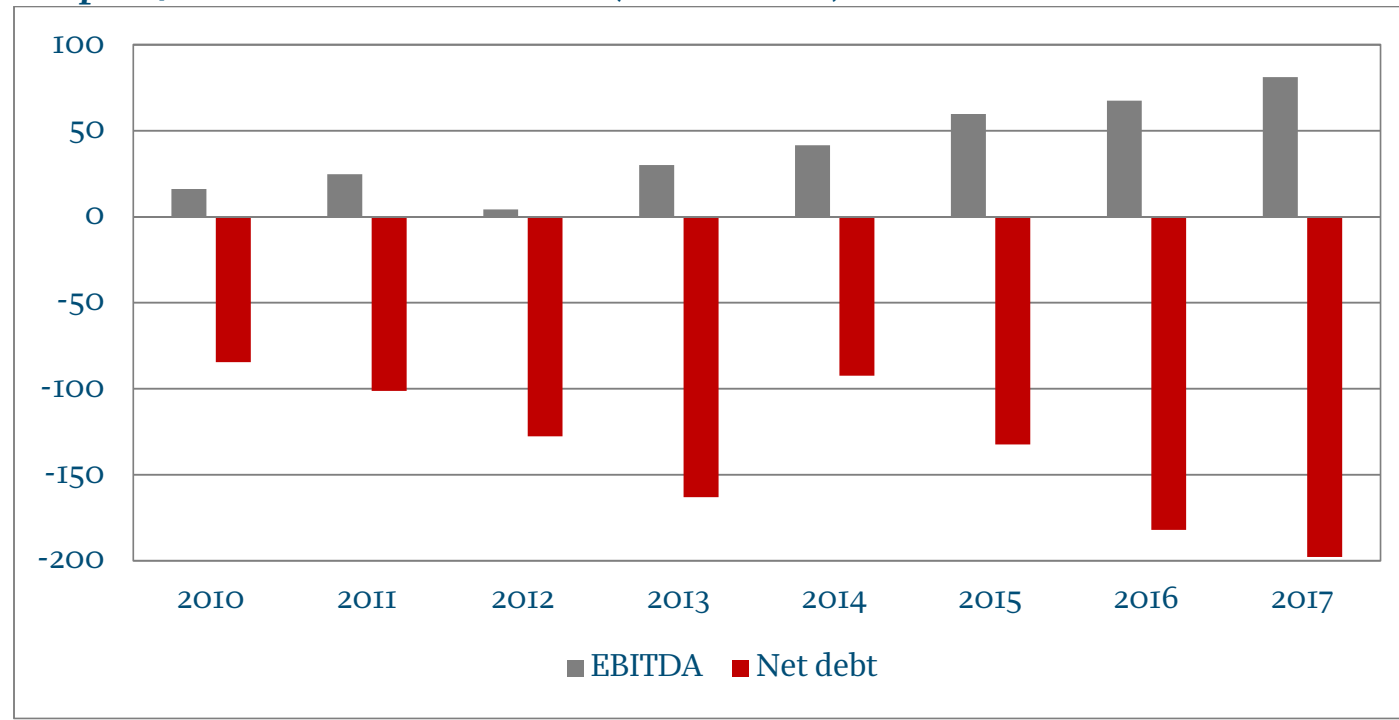

Source:

the graphical record produced by the author based on the data provided by FINA

\section{Betting}

Although in Croatia there are relatively few companies that hold a permit for the betting activity (only six companies), it is by far the largest segment within the gaming and betting sector. The analysis did not include HL, since this company generates only a smaller portion of the revenue from betting. On the other hand, Interigre company was fully included in the analysis, although only one of its parts (Stanleybet) operates in the betting sector (in a smaller scope, both absolutely and relatively). Interigre was also a part of the analysis of bookmakers and slot machine clubs. 
Table 4 Overview of the results of the main bookmakers in 2017

\begin{tabular}{|c|c|c|c|c|c|}
\hline HRK (million) & Revenue & Employed & EBITDA & EBIT & $\begin{array}{r}\text { Net } \\
\text { profit }\end{array}$ \\
\hline Super Sport & 570 & 945 & 352 & 347 & 292 \\
\hline Interigre & 434 & 859 & 67 & -2 & -2 \\
\hline Hattrick-PSK & 332 & 753 & I37 & I28 & 95 \\
\hline Germania Sport & $\mathrm{I} 28$ & 486 & $\mathrm{I} 2$ & 8 & 9 \\
\hline Favorit sportska Kladionica & 3 & IO9 & -15 & -16 & $-\mathrm{I6}$ \\
\hline Total (bookmakers) & 1,467 & 3,152 & 554 & 464 & 378 \\
\hline $\begin{array}{r}\text { Share in the overall } \\
\text { gambling and betting (\%) }\end{array}$ & 46 & 48 & 66 & 79 & 80 \\
\hline
\end{tabular}

Bookmakers are the biggest generators profitability in the gaming and betting sector, but they also operate in the segments of slot machines and casinos. When the impact of these big companies would not be excluded from the sector of casinos and slot machine clubs, their indicators would be distorted.

In the period 2010 - 20I7, the betting segment recorded the average annual revenue growth rate of $8 \%$, which was on the level of the gambling sector. However, if the 20I7 leap is excluded, the average annual growth amounts only to $4 \%$. The 2017 growth was generated by Super Sport, mostly in the segment of casinos. The company has been offering online casino games since 20I7, which brought the company the additional HRK IOO million revenue (graph I5).

\section{Graph 15 Change in the revenue structure of Super Sport} (comparison of 2010 and 2017 revenue structure, in \%)

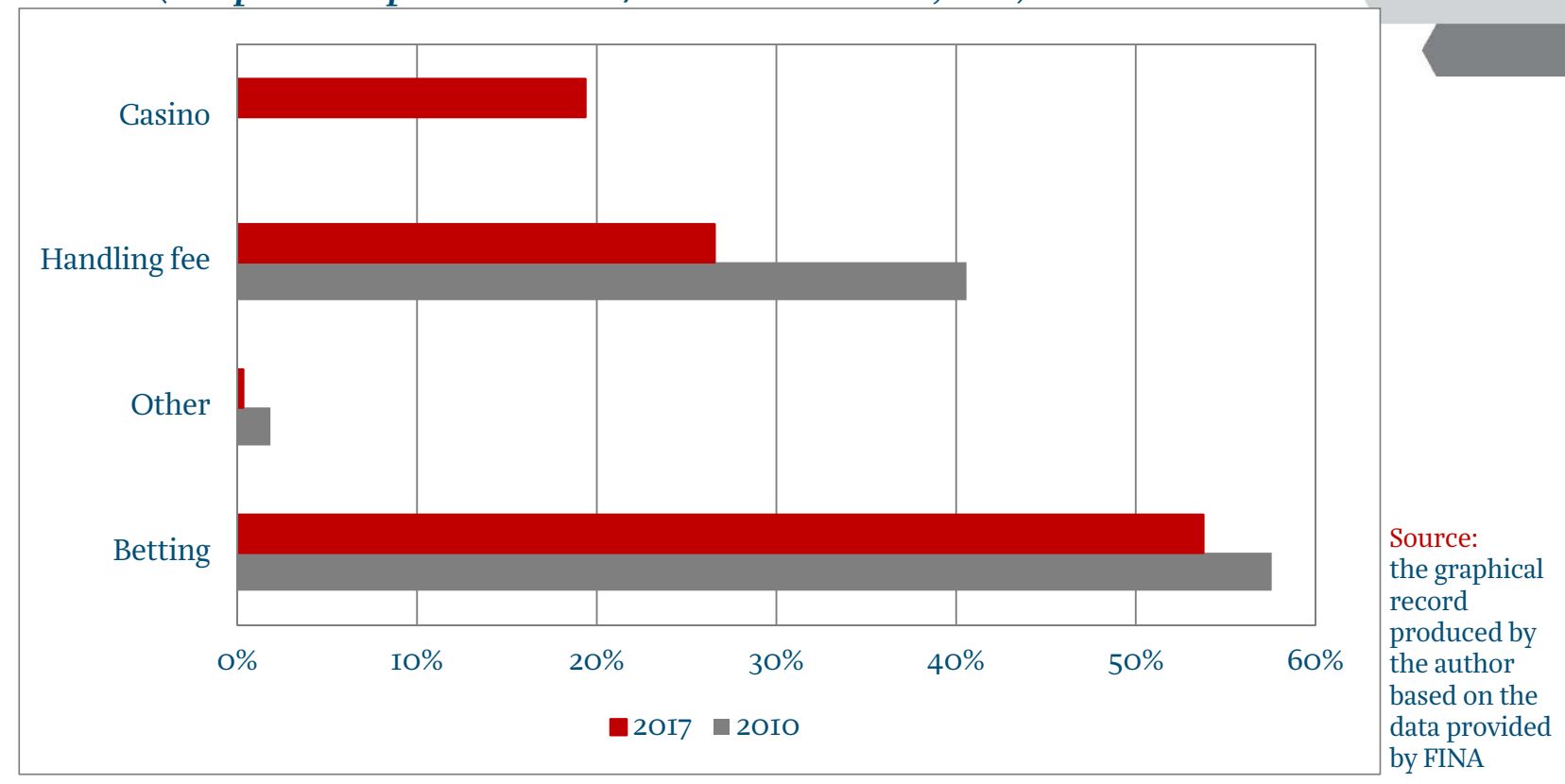

The profitability of the betting segment was slightly above the average of the gaming and betting sector (table 5), but it was largely defined by the results of Super Sport and Hattrick-PSK. Due to its size Super Sport had a dominant impact on the average indicators (the impact is a little bit smaller on the median). 
Table 5 Profitability in the betting segment in 2017 (in \%)

\begin{tabular}{|c|c|c|c|c|c|c|}
\hline Margins & EBITDA & EBIT & Net & ROE & ROGE & \\
\hline Super Sport & 62 & $6 I$ & $5 \mathrm{I}$ & 52 & 50 & \\
\hline Interigre & I5 & $\mathrm{O}$ & $\mathrm{O}$ & $-I$ & 2 & \\
\hline Hattrick-PSK & $4 \mathrm{I}$ & 39 & 28 & 67 & 36 & \\
\hline Germania Sport & IO & 6 & 7 & 50 & 37 & \\
\hline Favorit sportska Kladionica & $-42 I$ & -466 & -448 & 58 & -420 & \\
\hline Bookmakers average & 38 & 32 & 26 & 40 & $3 \mathbf{I}$ & \\
\hline & & & & & & \multirow{3}{*}{$\begin{array}{l}\text { Source: } \\
\text { authors, } \\
\text { based on the } \\
\text { data provided } \\
\text { by FINA }\end{array}$} \\
\hline Bookmakers median & $\mathrm{I} 5$ & 6 & 7 & 52 & 36 & \\
\hline $\begin{array}{r}\text { Gaming and betting } \\
\text { sector average }\end{array}$ & 27 & 19 & 15 & 30 & 22 & \\
\hline
\end{tabular}

In the period 2010 - 2015 the headcount in the betting segment reduced (graph I6), but it grew in the last two years of the analysis.

Graph I6 Employment (HRK ooo) and personnel cost (\%) in the betting segment

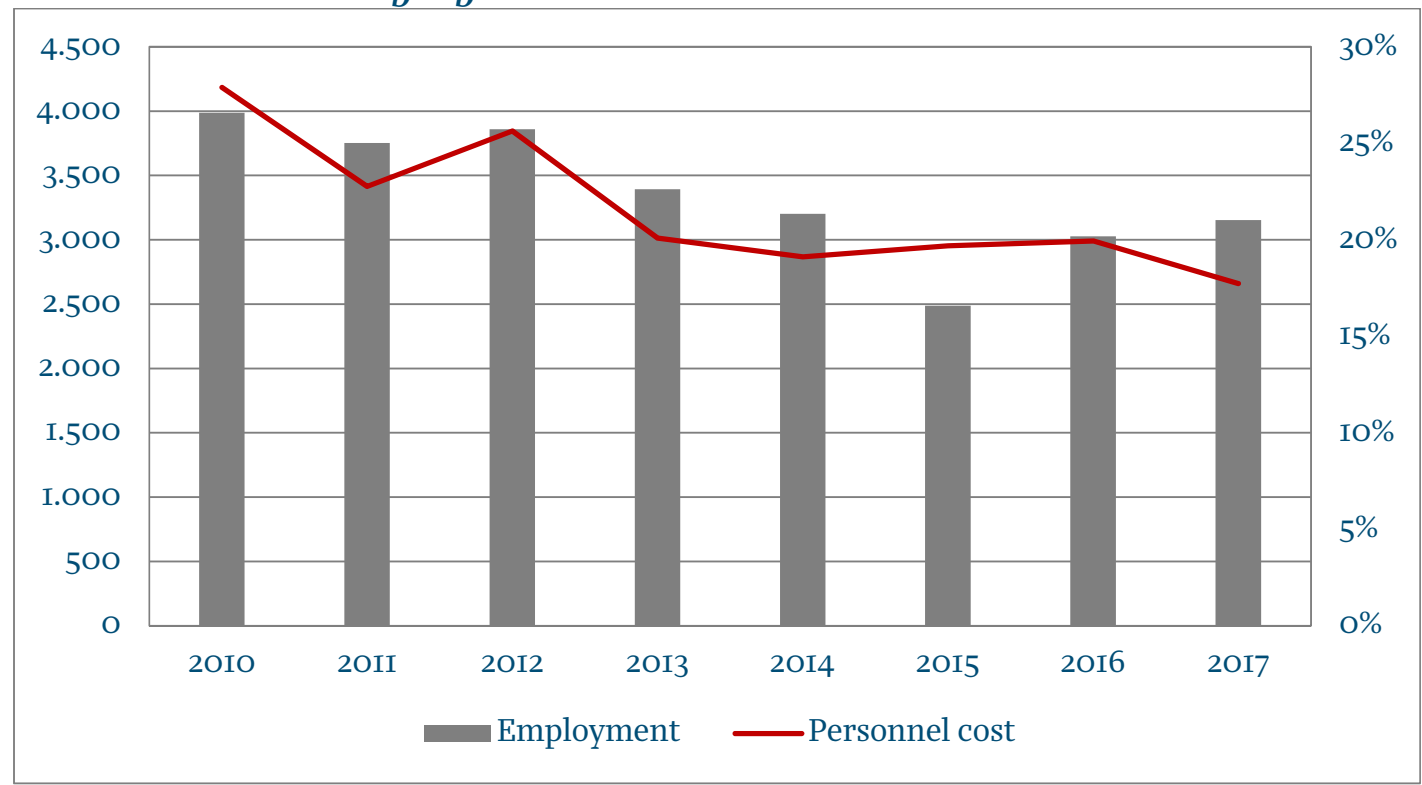

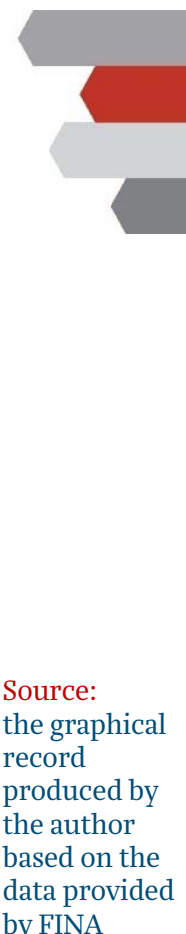

data provided by FINA

The betting segment recorded a headcount productivity growth (graph I7), which was probably a result of redirection of players to online games. Moreover, the salaries grew about 4\% per year on average during the observed period. 


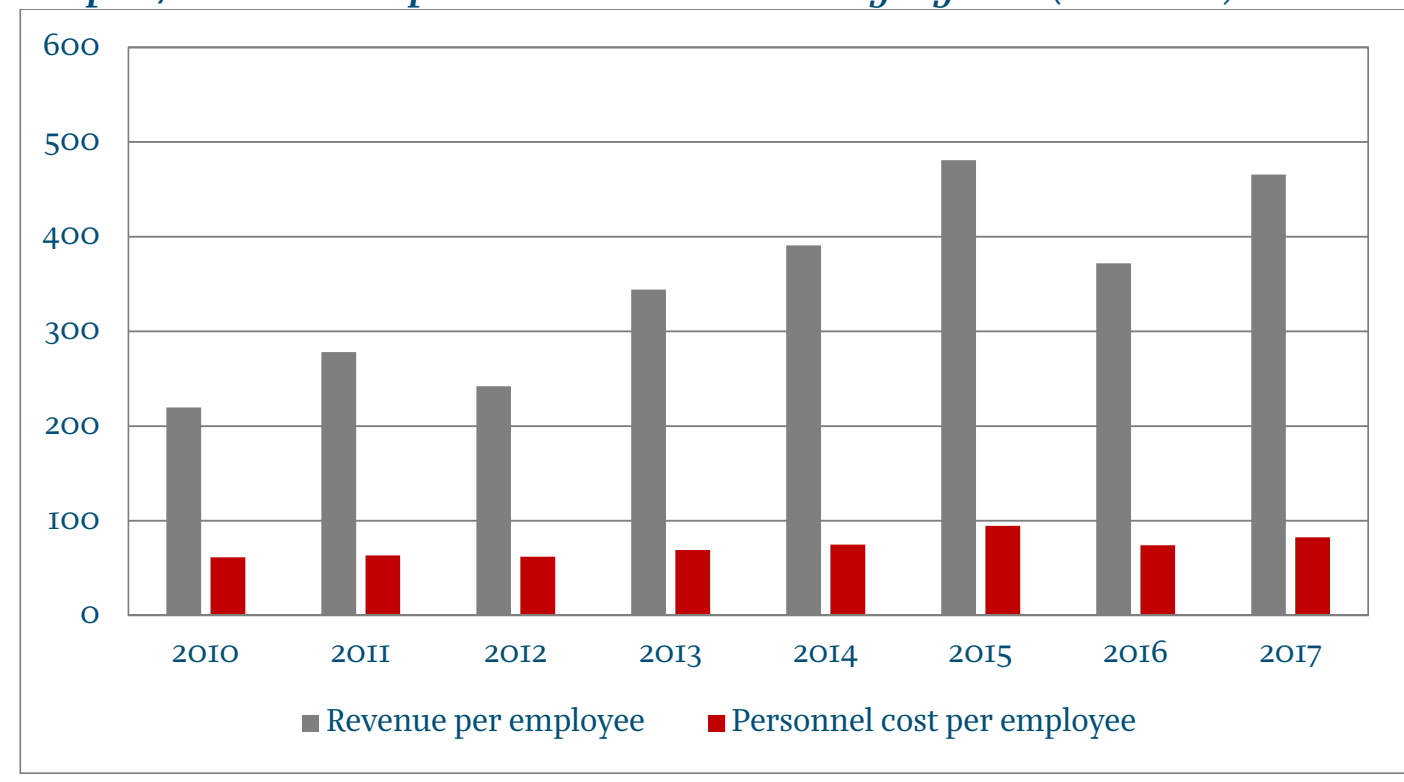

Source:

the graphical record produced by the author based on the data provided by FINA

In 20I7, despite the challenges they faced (like unfair and illegal competition), the betting segment achieved enviable results in net profit and net margin (graph I8). The domination of the Super Sport bookmaker was evident. The EBITDA margin in the betting segment exceeded $30 \%$ in the successful years (graph 19). However, taking into consideration the dominant role of Super Sport, these financial indicators should be taken with a grain of salt.

\section{Graph 18 Net profit (HRK million) and net margin in the betting segment (\%)}

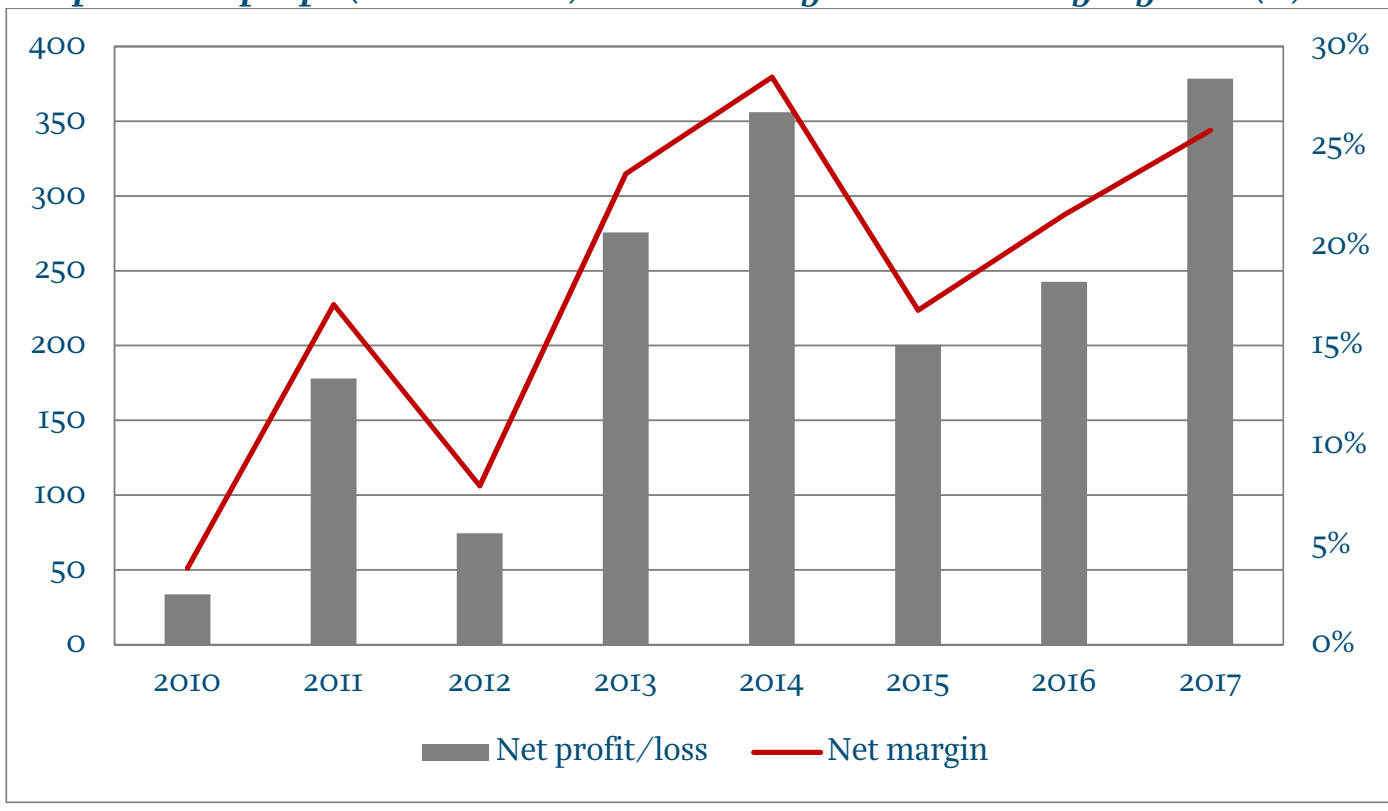

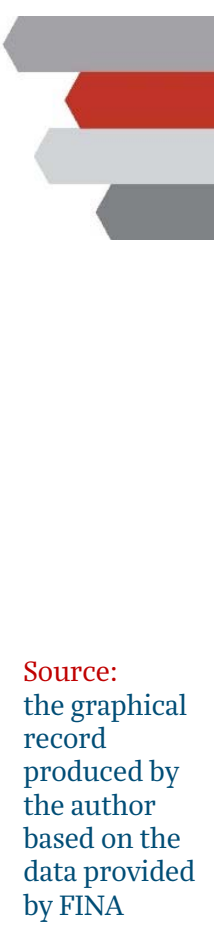


Graph 19 Profitability in the betting segment (in \%)

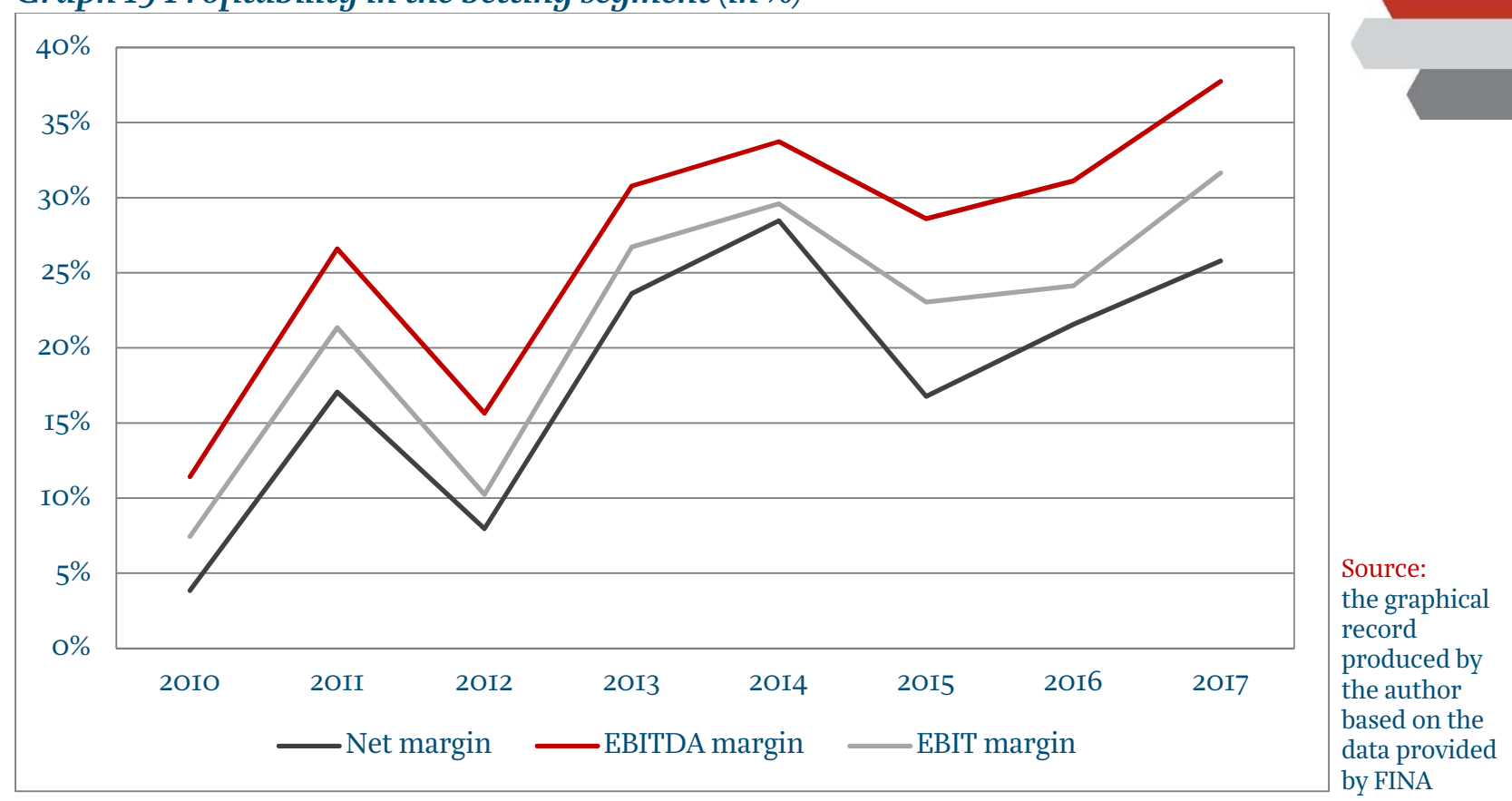

The liquidity of the gaming and betting sector was appropriate - the current liquidity indicator was high (the highest in the gaming and betting sector), with a continuing upward trend (graph 20 ), and the own financing amounted to a favourable $70 \%$.

Graph 20 Current liquidity and indebtedness in the betting segment

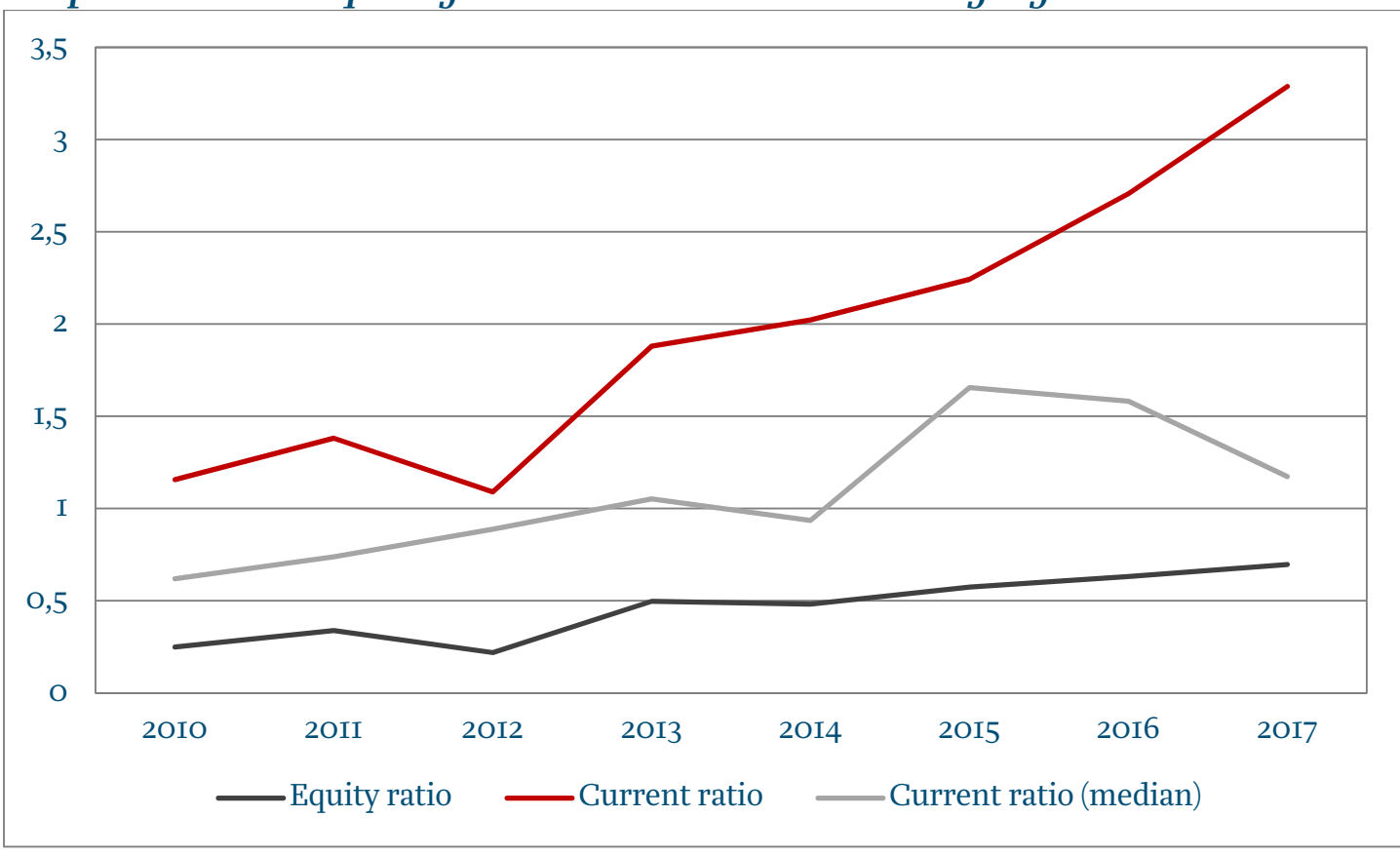

Source:

the graphical record produced by the author based on the data provided by FINA 


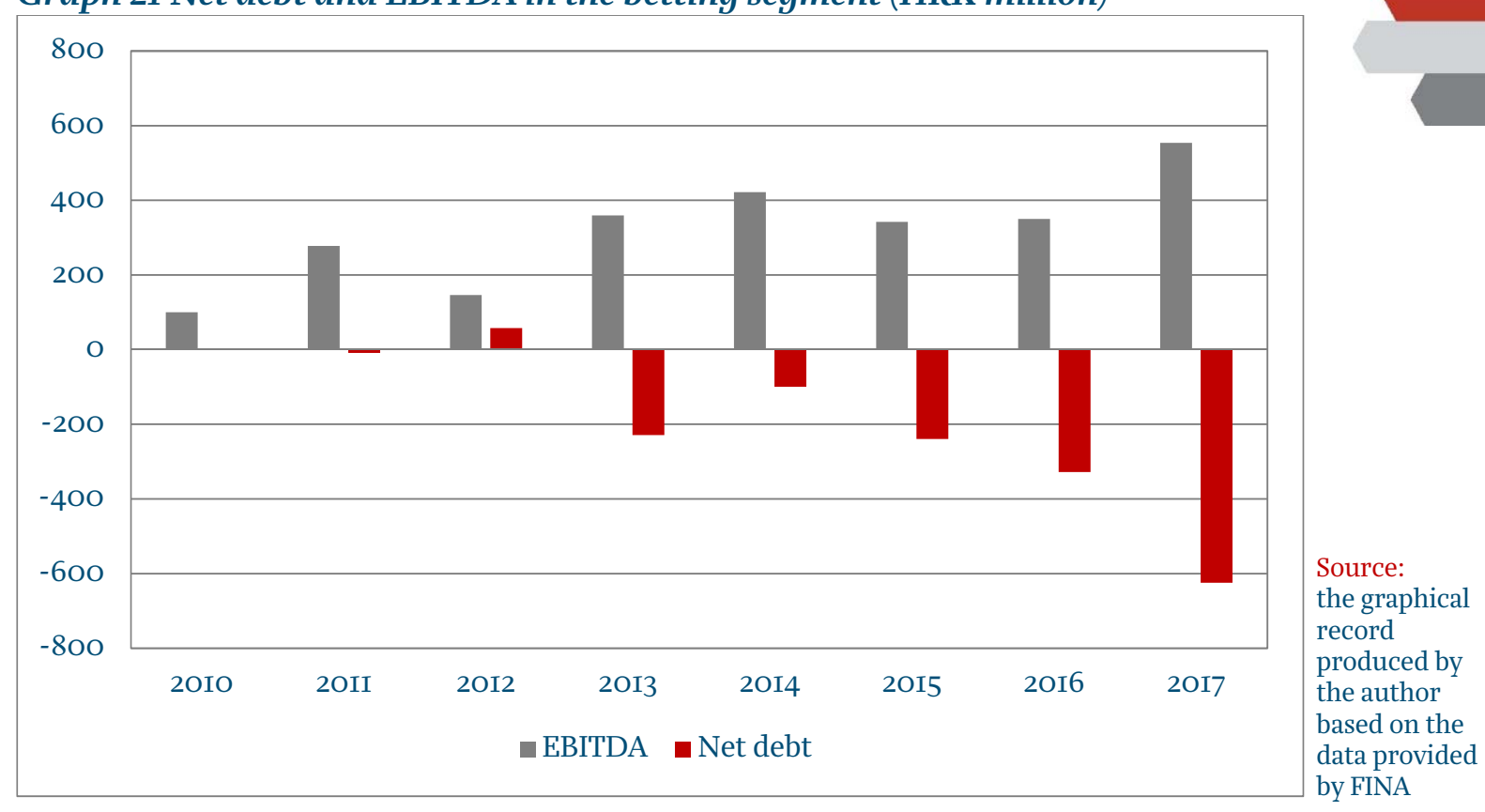

In the last five years of the observed period, the bookmakers operated with a positive cash flow. The amount increased over the years, with a simultaneous growth in generating cash flow approximated by the EBITDA indicator. Super Sport is perceived as the main cause of such trend. However, the companies Interigre and Germania are also debt-free, whereas intensive deleveraging was recorded at Hattrick-PSK.

Slot machine clubs and casinos

The market segment of casinos and slot machine clubs showed similar trends. For the needs of the analysis, HL and some other largest bookmakers were excluded from the segment of slot machine clubs and casinos, although they've operated in this segment, but it was not their dominant source of revenue. This segment is very concentrated, dominated by the first two players - Interigre and International Evona.

The analysis included all companies that operated in this segment in 20I7, but also all their preceding companies, that is the companies that had been subject to a merger in the past seven years.

The table 6 shows that the biggest market participants were accounted for about $50 \%$ of the revenue and headcount, but at the same time they generates only Io\% of the net revenue of the gaming and betting sector. 
Table 6 Profitability in the segment of slot machine clubs and casinos

\begin{tabular}{|c|c|c|c|c|c|c|}
\hline & $\begin{array}{r}\text { Revenue } \\
\text { (HRK } \\
\text { million) } \\
\end{array}$ & Employed & $\begin{array}{r}\text { EBITDA } \\
\text { (HRK } \\
\text { million) } \\
\end{array}$ & $\begin{array}{r}\text { EBIT } \\
(\text { HRK } \\
\text { million) } \\
\end{array}$ & $\begin{array}{r}\text { Net profit } \\
\text { (HKR } \\
\text { million) } \\
\end{array}$ & \\
\hline Interigre & 434 & 859 & 67 & -2 & -2 & \\
\hline International Evona & I82 & 207 & 50 & 37 & 30 & \\
\hline Wettpunkt & 95 & 72 & I7 & 9 & 9 & \\
\hline Adria Casino & $6 \mathrm{I}$ & I5I & 7 & 4 & 3 & \\
\hline $\begin{array}{r}\text { Mulino turizam i } \\
\text { hotelijerstvo }\end{array}$ & 52 & 48 & 20 & 7 & 5 & \\
\hline Multi-Star & 46 & 86 & II & 7 & 5 & \\
\hline Moneo & 45 & 82 & 9 & 8 & 7 & \\
\hline Major Internacional & 42 & 94 & 8 & 4 & 3 & \\
\hline Brut & 40 & 95 & I3 & 7 & 6 & \\
\hline Puni broj & 38 & 25 & 25 & 22 & I8 & \\
\hline $\begin{array}{r}\text { Top Io (casinos and slot } \\
\text { machine clubs) }\end{array}$ & I,OO6 & I,659 & 216 & 93 & 77 & \\
\hline $\begin{array}{r}\text { Total (casinos and slot } \\
\text { machine clubs) }\end{array}$ & I,598 & 3,071 & 268 & 69 & 49 & $\begin{array}{l}\text { Source: } \\
\text { authors, }\end{array}$ \\
\hline $\begin{array}{r}\text { Share in the overall } \\
\text { gambling and betting (\%) }\end{array}$ & $5 \mathrm{I}$ & 47 & 32 & 12 & IO & $\begin{array}{l}\text { based on the } \\
\text { data provided } \\
\text { by FINA }\end{array}$ \\
\hline
\end{tabular}

In the period 2010 - 20I7, the segment of slot machine clubs and casinos recorded the average annual growth rate of $12 \%$, which was double the average annual growth rate of the overall gambling and betting sector (6\%). In the past decade, this segment recorded the highest number of mergers, with Interigre company occupying the top position as a consolidator.

Table 7 Profitability in the segment of slot machine clubs and casinos in 2017 (in \%)

\begin{tabular}{|c|c|c|c|c|c|}
\hline Margins & EBITDA & EBIT & Net & ROE & ROCE \\
\hline Interigre & I5 & $\mathrm{O}$ & $\mathrm{O}$ & $-I$ & 2 \\
\hline International Evona & 28 & 20 & I7 & 48 & 39 \\
\hline Wettpunkt & I8 & IO & IO & II3 & $4 \mathrm{I}$ \\
\hline Adria Casino & II & 6 & 5 & 32 & I9 \\
\hline Mulino turizam i hotelijerstvo & 37 & 14 & 9 & 5 & 6 \\
\hline Multi-Star & 23 & 14 & 12 & 26 & 22 \\
\hline Moneo & I9 & 17 & 15 & 29 & 26 \\
\hline Major Internacional & 20 & II & 7 & I5 & $\mathrm{I} 2$ \\
\hline Brut & 32 & I8 & I4 & $2 \mathrm{I}$ & I9 \\
\hline Puni broj & 65 & 59 & 48 & IO4 & 88 \\
\hline $\begin{array}{r}\text { Slot machine clubs and casinos average } \\
\text { (all companies) }\end{array}$ & 17 & 4 & 3 & 6 & 4 \\
\hline $\begin{array}{r}\text { Slot machine clubs and casinos median } \\
\text { (all companies) }\end{array}$ & I8 & 6 & 4 & I5 & 7 \\
\hline $\begin{array}{r}\text { Gaming and betting } \\
\text { sector total }\end{array}$ & 27 & 19 & I5 & 30 & 22 \\
\hline
\end{tabular}

The profitability of the segment of slot machine clubs and casinos was lower than the average profitability of the gaming and betting sector due to a lower profitability of casinos - they generated losses on the operating result level (table 7). The median margins show slightly higher 
numbers than the average, which is the result of lower profitability of larg er market players, Interigre in particular. The below average profitability of Interigre was the result of a more intensive investment activityı and cancelling of the deferred tax assets.

The employment in the segment of slot machine clubs and casinos grew about $5 \%$ per year, but it was significantly lower than the revenue growth that amounted to I2\% a year. Therefore, the gross salaries dropped from about $24 \%$ of the revenue in 2010 to $20 \%$ of the revenue in 2017 . (graph 22).

\section{Graph 22 Employment (HRK ooo) and personnel cost (\%) in the sector of slot machine clubs and casinos}

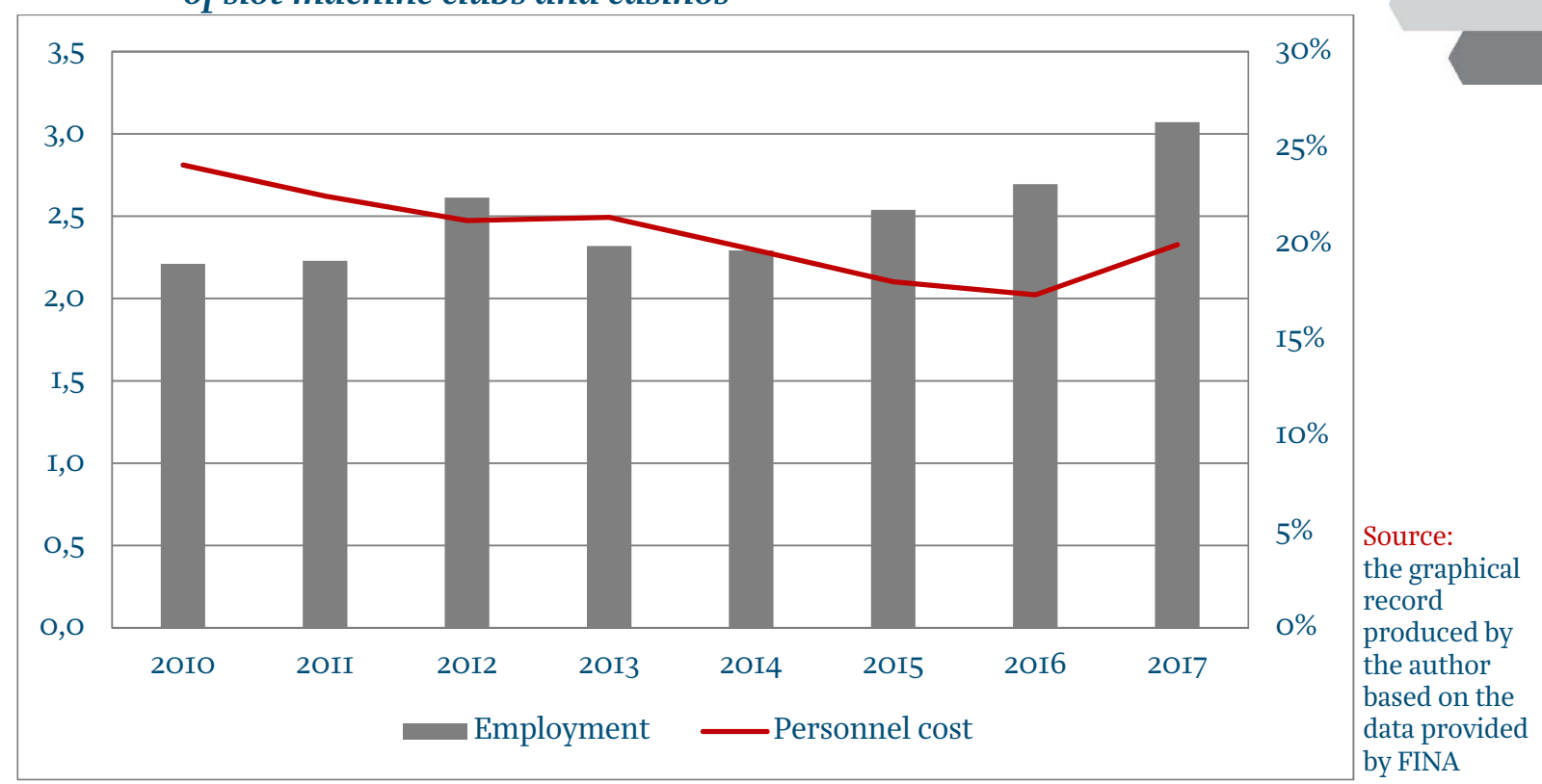

The growth of the tourism sector and the economic recovery of the Republic of Croatia had a positive effect on the segment of slot machine clubs and casinos, especially in the coastal towns and cities. The segment managed to cover the losses accumulated in the period 2OIO - 2OI2. The decline of profitability in the segment of slot machine clubs and casinos in 2017 (graph 24) was a consequence of the underperformance of the leading company, Interigre. Apart from 20I7, it can be observed that EBITDA margin stabilised at about 20\%, and EBIT at about IO\% (graph 25). The underperformance in 2017 can also be partly attributed to a stronger competition, after the Ministry of Finance issued new licences granting the right to organise gambling in casinos.

\footnotetext{
${ }^{\mathrm{I}}$ Interigre is a company with three casinos, 80 slot machine clubs and IIo betting shops. In 20I6, the company participated in mergers, which led to a fall in profitability and a rise in costs caused by the acquisitions and integration.
} 
Graph 23 Revenue and gross salary per employee in the segment of slot machine clubs and casinos (in HRK oOo)

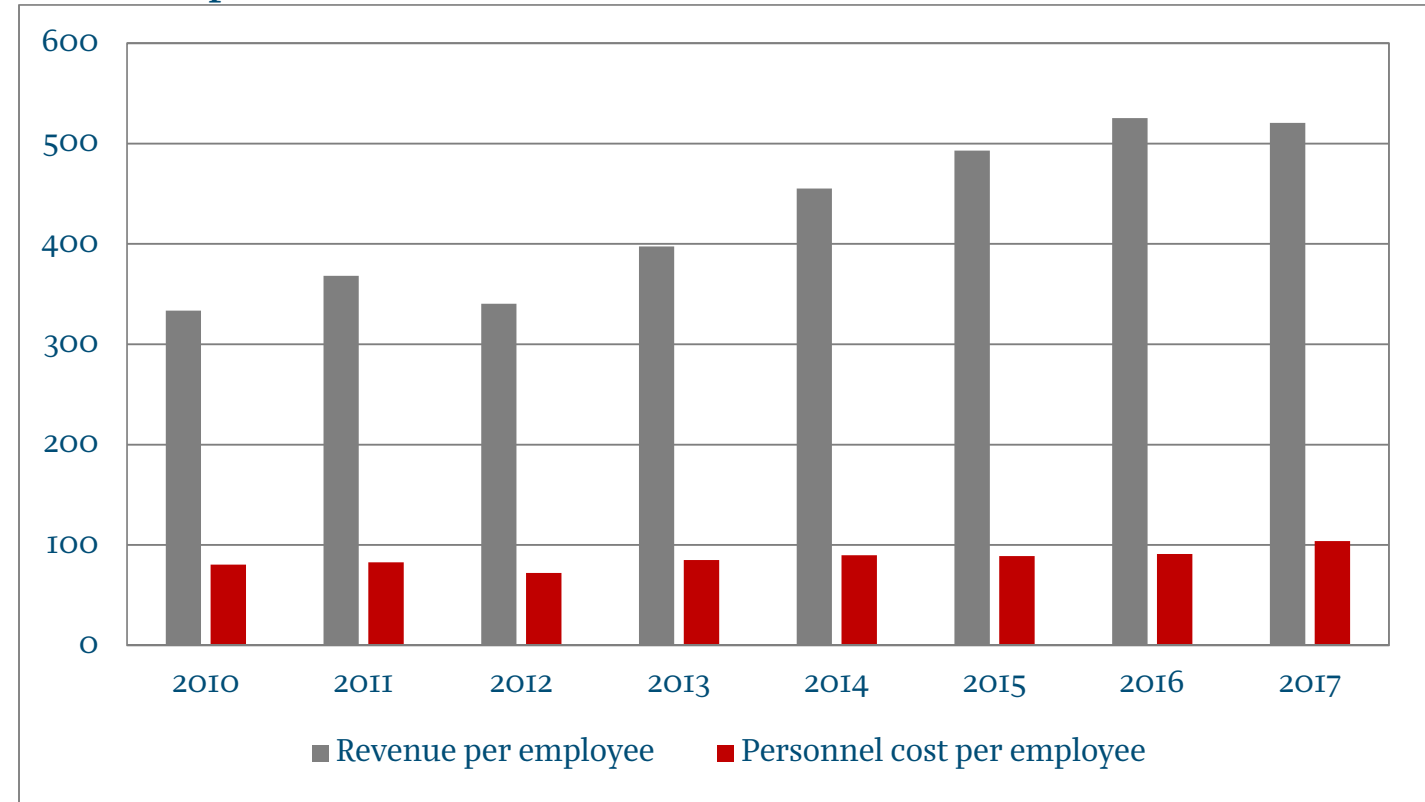

Graph 24 Net profit (HRK million) and net margin (in \%) in the segment of slot machine clubs and casinos

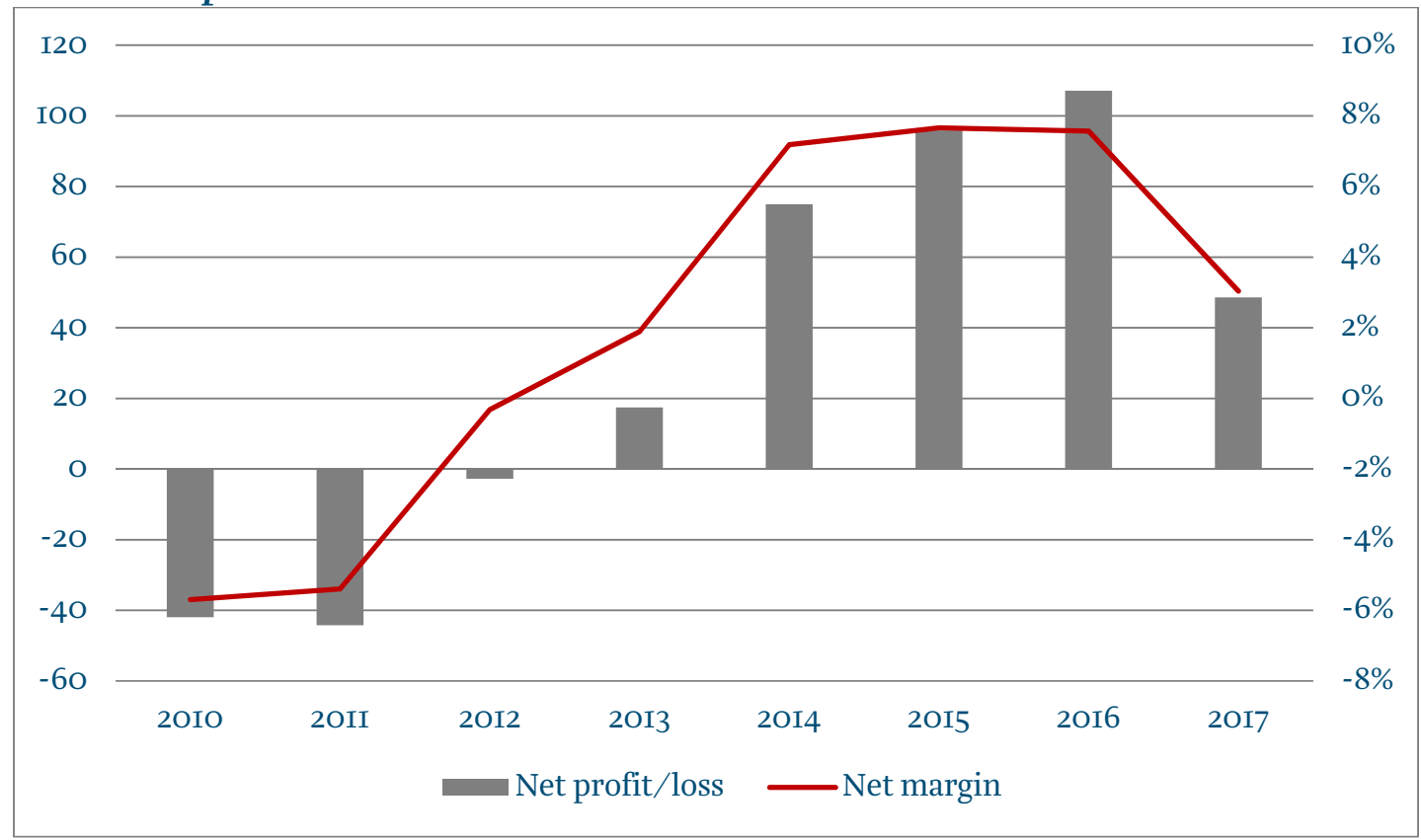

Source:

the graphical record

produced by the author based on the data provided by FINA

The asset turnover ratio in the segment of casinos and slot machine clubs was rather stable (I.8 on average for fixed assets, i.e. I for the total assets). The segment of casinos was also more capital intensive because of the procurement of equipment and somewhat more capital intensive business model (which can be observed by comparing the EBITDA and EBIT margin). 


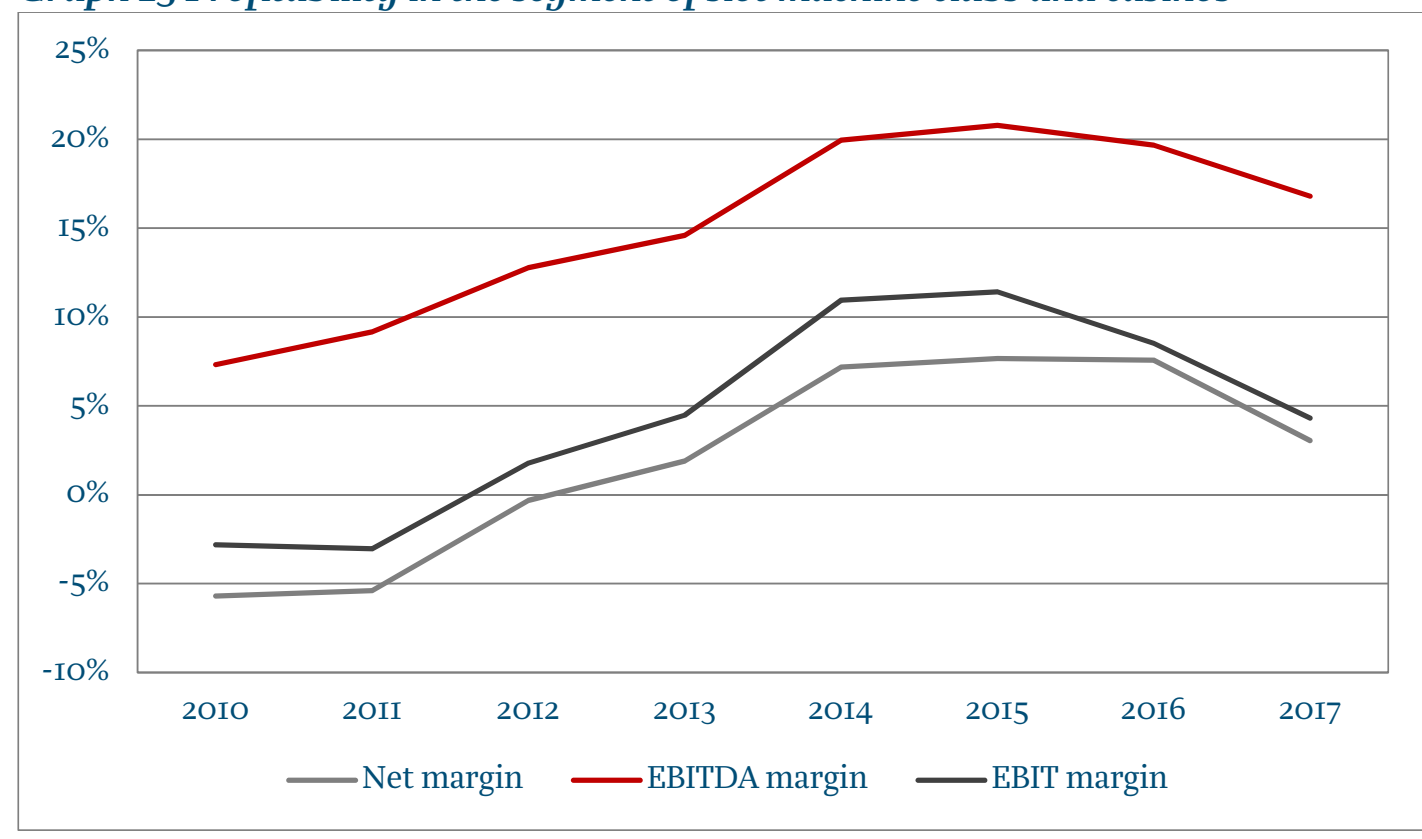

Source: the graphical record produced by the author based on the data provided by FINA

The slot machine clubs and casinos improved their liquidity, with the indebtedness being on an acceptable level and with a positive growth trend (graph 26). The performance indicators of the slot machine clubs and casinos were substantially lower than the performance indicators in the betting segment.

\section{Graph 26 Current liquidity and indebtedness in the segment of slot machine clubs and casinos}

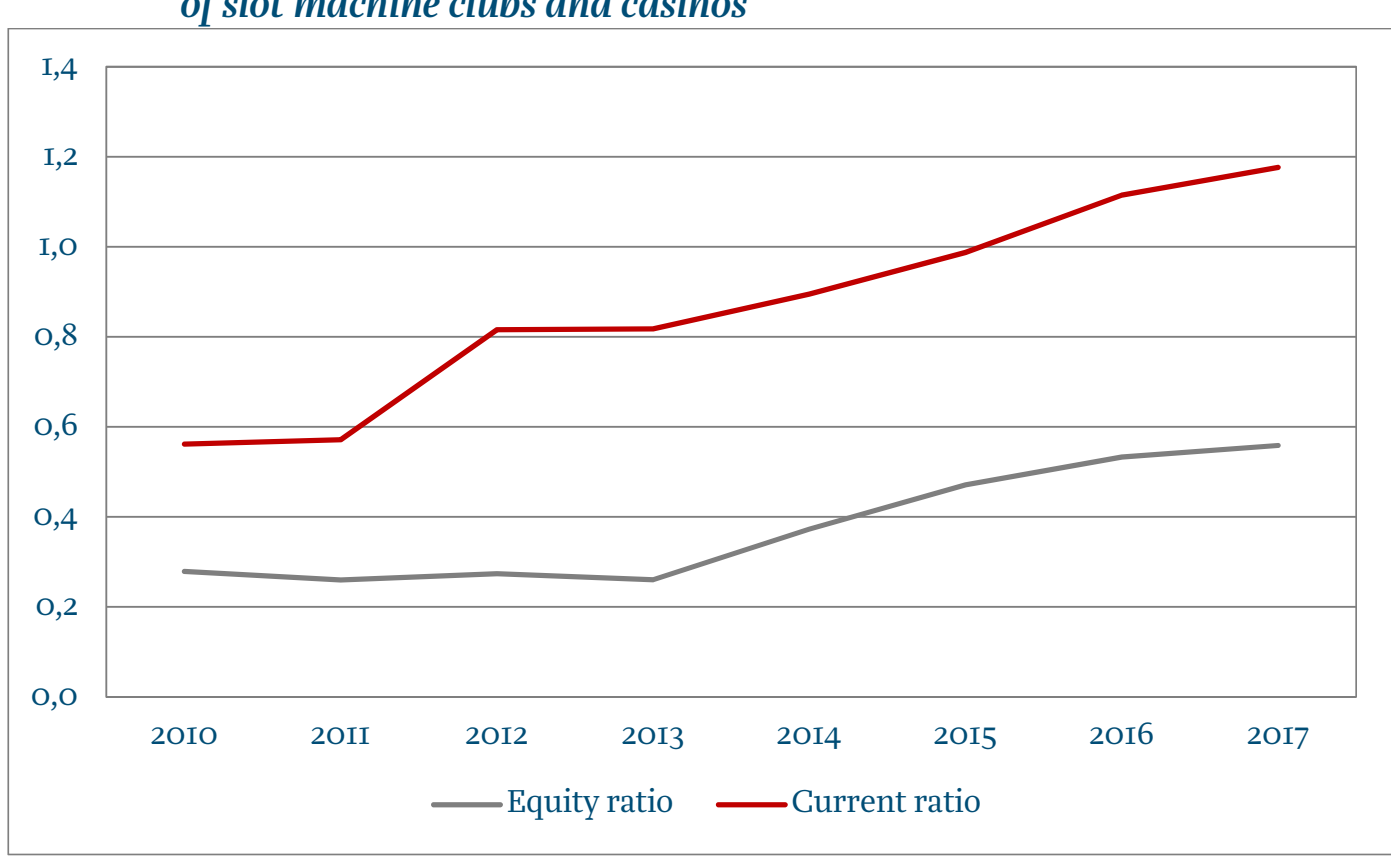

Source:

the graphical record produced by the author based on the data provided by FINA 


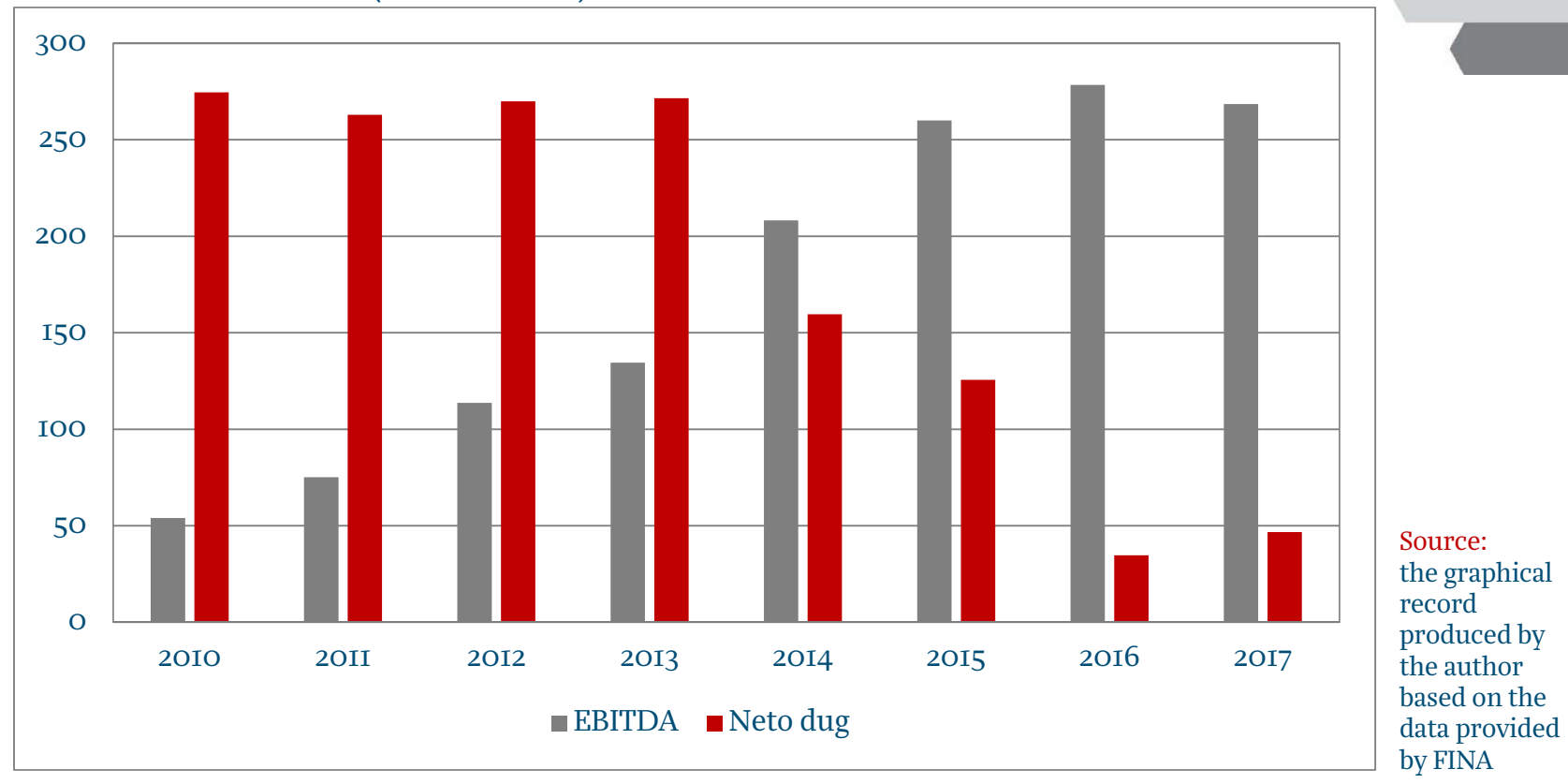

In the past couple of years, the segment of slot machine clubs and casinos was marked by a decrease in indebtedness and increase of profitability. The net debt was covered by the annual EBITDA margin, which made the collection of debts certain (graph 27).

\section{Fiscal Effect of Fees and Taxes on Gambling in Croatia}

The text below analyses the overall direct fiscal effects of gambling on the budget revenue. They include fees and taxes paid by the gambling operators and winners in Croatia.

The gambling taxes and fees can be divided into two groups. The first group includes taxes on lottery games, gambling and betting. These are the fees paid by the gambling operators on a monthly basis for:
a) organisation of betting,
b) organisation of gambling at slot machine clubs,
c) organisation of gambling at casinos,
d) organisation of lottery games,

and on the annual basis for:

e) organisation of gambling at slot machine clubs,

f) organisation of gambling at casinos,

g) organisation of betting.

According to the European Commission methodology (European Commission, 20I9), the annual fees primarily include fees referring to obtaining the business and professional permits, and the monthly fees represent a sort of classic tax on lottery, gambling and betting.

The second group includes taxes on winnings from gambling paid by the players when they win and they comprise: a) tax on winnings from lottery games and b) tax on winnings from betting. 
Graph 28 shows gambling taxes and fees in the Republic of Croatia in the period 2010 - 2017. Such revenues recorded growth in both the absolute and relative amounts. They doubled in the observed period (from HRK 657 million in 2OIO to HRK I.2 billion in 2OI7), which made $0.9 \%$ of the total revenue from taxes and contributions. Their biggest portion of the total fees primarily comprises fees paid by gambling operators. Then, there are taxes on winning from gambling paid by winners - more than $90 \%$ of that sum goes to tax on winnings from betting. The 2014 changes if the tax policy contributed to a strong growth of taxes on winning in the period 2015 $-2017$.

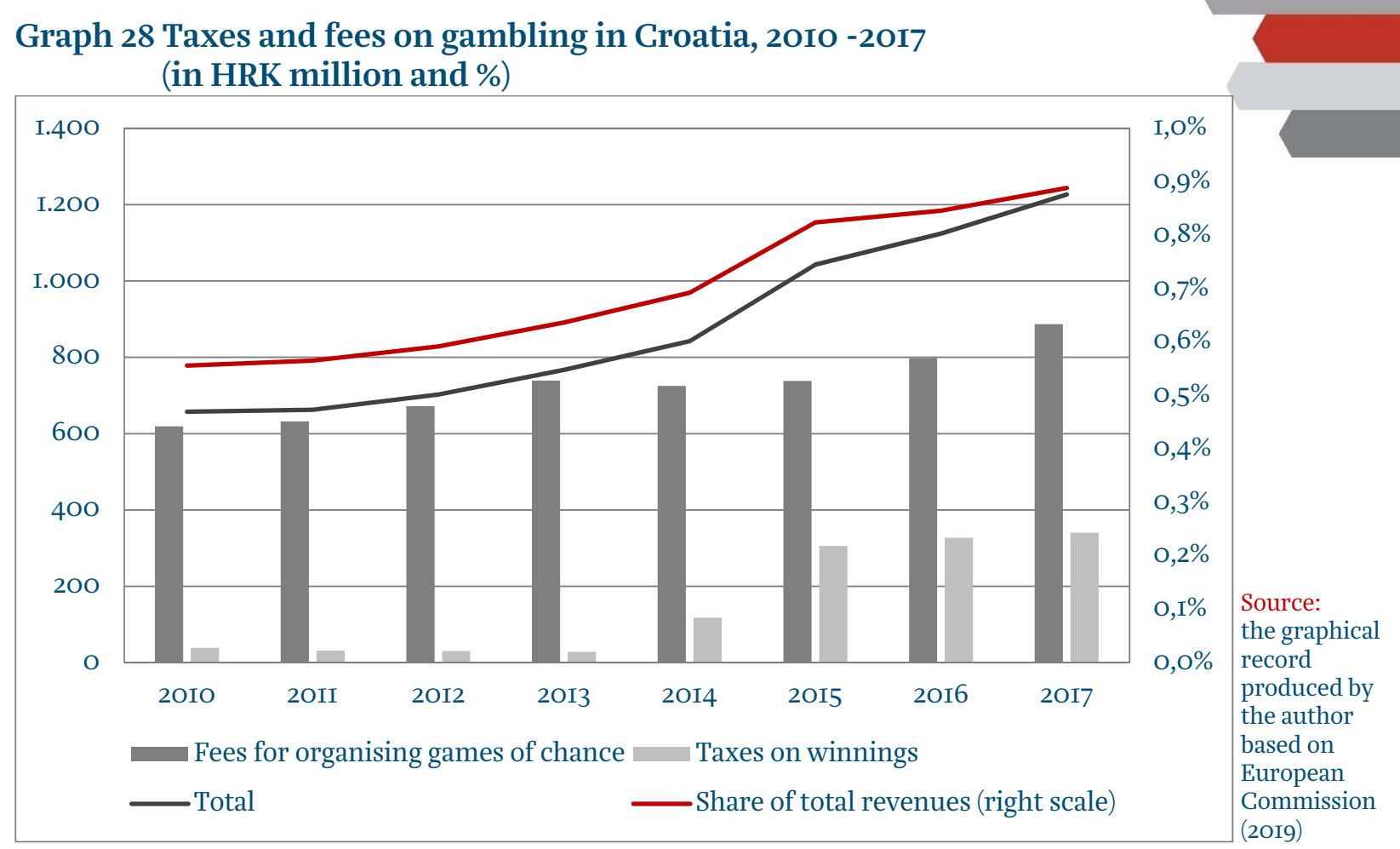

Many authors (e.g. Torre, Zoričić and Škifić, 20Io) emphasise taxation as the main rationale behind the liberalisation of the gambling market. However, this is not the case in Croatia. There are two main reasons for this. Firstly, the direct contribution of gambling to the budget revenue is lower than $\mathrm{I} \%$. It is a relatively small amount compared to the tobacco industry, where the products also fall into the category of vices and cause addiction problems. Secondly, the taxes on gambling make about $0.4 \%$ of the total budget revenue on average on the EU level. Therefore, it cannot be said that the market liberalisation in the past ten years has primarily had a budgetary purpose (European Commission, 2OI9).

The direct effect of the gambling sector on the budget revenues was analysed first. However, the gambling operators indirectly contribute to the budget revenue. If they generate profit, as legal entities, they are obliged to pay profit tax, and they also pay contributions and other duties for their employees. Furthermore, in order to get a realistic picture of the overall revenue that the government generates from gambling, it is necessary to include the HL profit. 


\section{Challenges of the Gambling Market and Possible Changes of Regulations}

The analysis of the gambling market is based on 2017 data, and the continuation of the positive business performance is expected in the following years. This is also visible in the 2018 financial statements of the main market participants. It is possible to achieve the record result on the level of the entire sector in this year, and especially in the segment of sports betting, which can be largely attributed to the success and long participation of the Croatian football national team in the World Cup in Russia.

Besides, in 2019, the Ministry of Finance issued an order for the ban of work for I4 international gambling operators. These were mostly online bookmakers that offered their services in Croatia illegally.2 This was the beginning of dealing with the issue of illegal bookmakers, and it definitely turned a portion of the "black" market into the revenue of the national gambling operators. According to the European Gaming and Betting Association, the share of the grey market in the Republic of Croatia amounts to 38\%, i.e. about HRK 2 billion (EGBA, 2OI7).

The consolidation of companies, that is the reduction of the number of companies in the industry, continues, which will affect the rise in market share of the main market participants due to takeover of smaller competitors, primarily in the segment of betting and slot machine clubs.

\section{Graph 29 The share of land-based and online gambling in EU (in \%)}
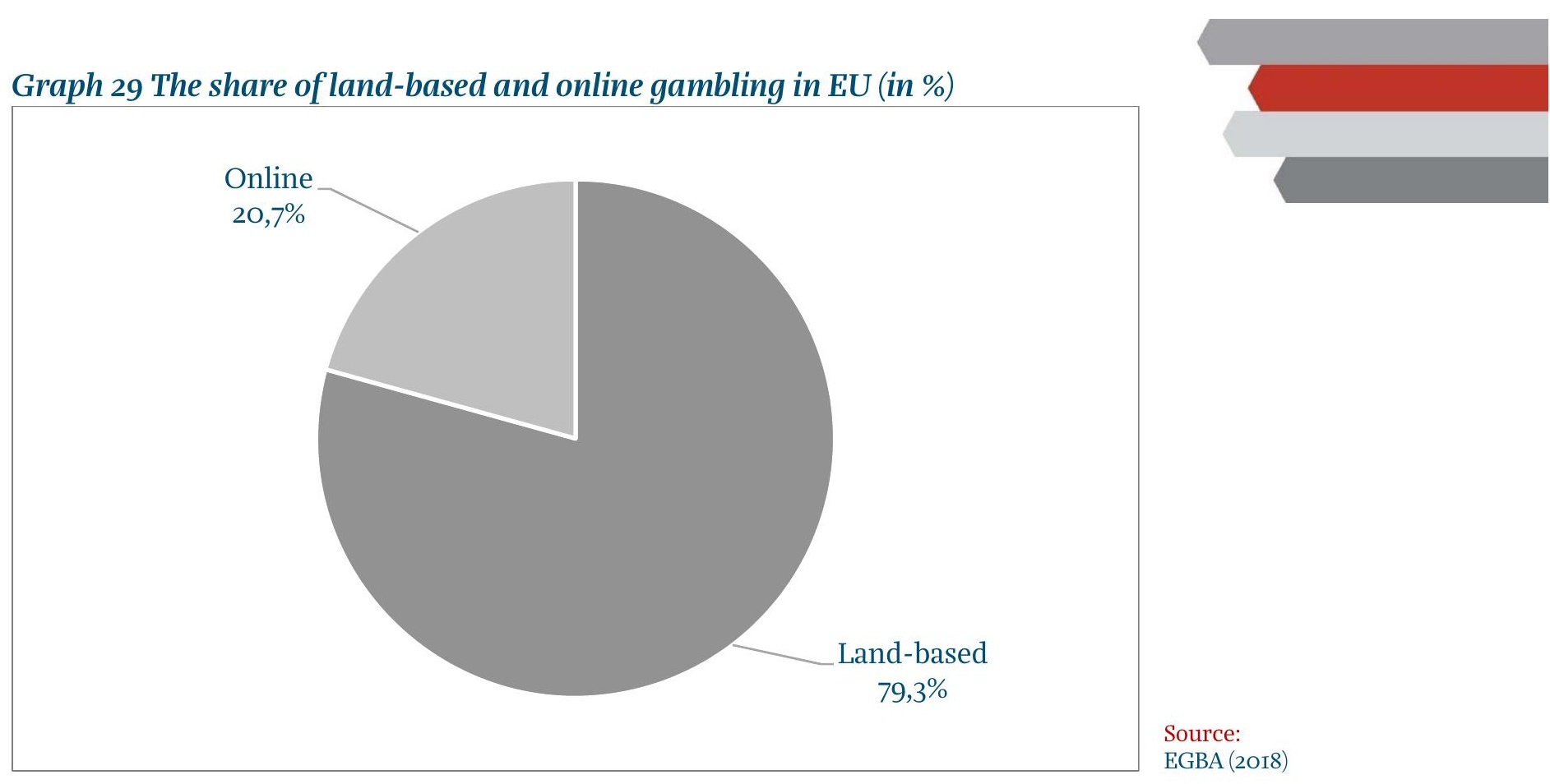

${ }^{2}$ The prevention of illegal activities is regulated by the Ordinance on the Implementation of the General Tax Act (OG 45/19) that came into force at the beginning of May 2019. 

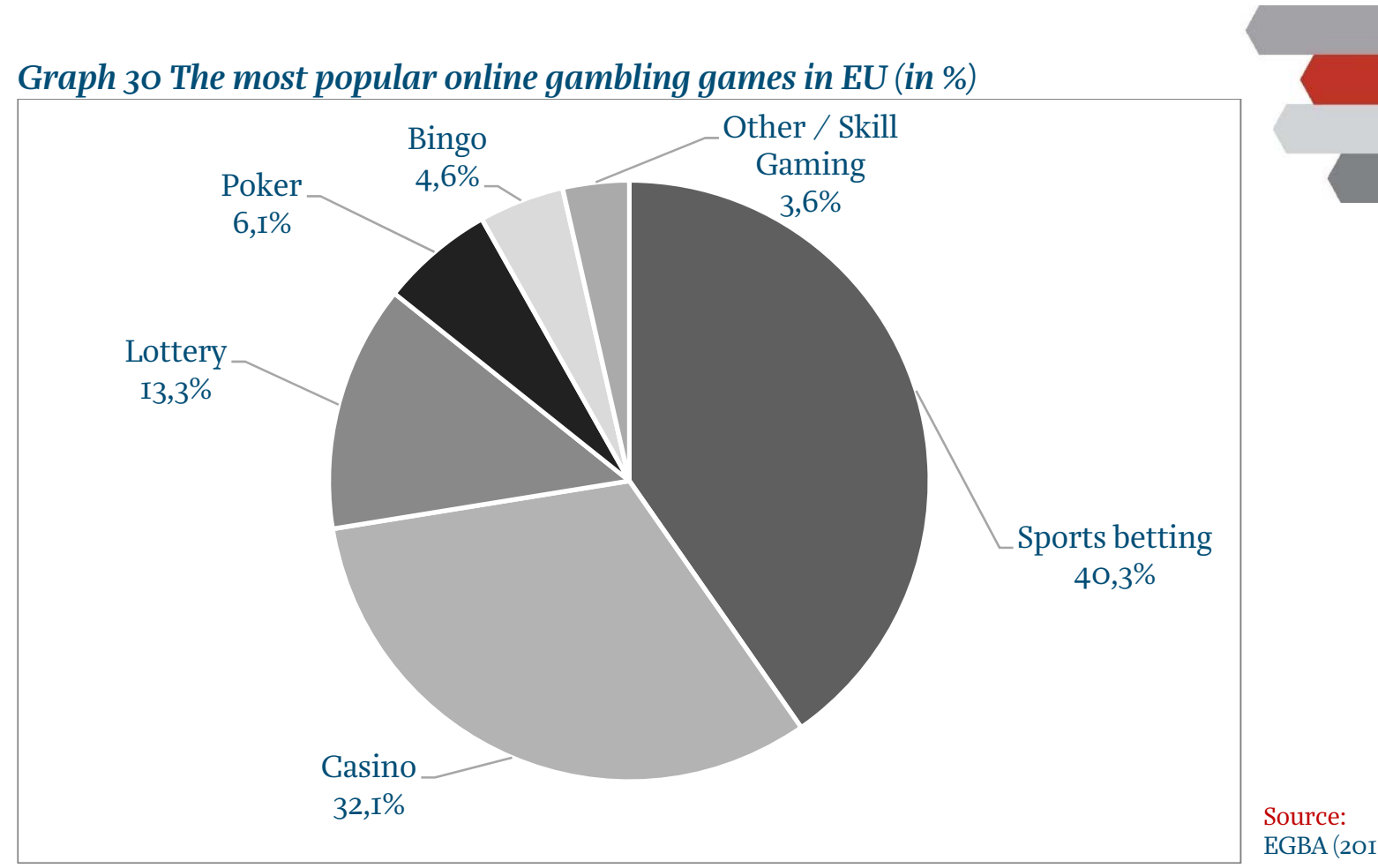

Digitalisation is an important factor of changes, for both the operators and the players. The players have been increasingly using smartphones, and the personalised user experience becomes more important to them. This is especially the case with the younger players (the millennials). In EU, online gambling makes more than $20 \%$ of the market (graph 29). In EU countries EUR I9. 6 billion was spent on online gambling in 20I7, and it is expected that the amount would increase to EUR 24.7 in 2020 (EGBA, 2OI8). To put it briefly, the companies that adjust faster and better to trends, will deliver better market outcomes. Since the most popular online gambling games include betting and casino (graph 30), the previous analysis showed that the companies that followed trends and developed this form of business activity turned out as market winners (e.g. Super Sport, Interigre, and even HL, which achieves satisfactory results in the segment of online casinos).

In particular, the issue of digitalisation must be observed from the perspective of the common EU market, where there have been attempts in the past couple of years to reach a legal consensus on online gambling, since the member countries have different legislation. In the majority EU member countries the organising of online games requires a licence, whereas in a smaller number of the member countries there is monopoly involved in gambling, including the online gambling. There are few member countries where gambling is prohibited, but this does not prevent players from these countries to gable with the operators from other countries.

The future of the gambling sector in the Republic of Croatia will define the relation of the government not only to this sector, but also to HL that remained the only domestic state-owned operator. Strengthening of HL in the gambling segments the company has no monopoly of (betting, slot machine clubs and casinos) will depend on the development of the regulations and tax policy. The change of taxes on winning from betting in 2015 caused a substantial increase in this type of budget revenue, which even exceeded the monthly fee paid by the operators. Since the tax on winning has a destimulating effect on (small) players and boosts illegal betting, the option of increasing the fees paid by the betting operators should be considered, as well as the return of the tax exemption for small winning that was repealed at the beginning of 2015. This would shift the taxation burden from the players to the operators. Besides the above-mentioned change in the tax structure, a further improvement in the collection of taxes and turnover 
control is possible by means of improvement of the fiscal system that is still non-existent in casinos and slot machine clubs (Article 64 of the General Tax Act).

The growth of the gambling market has affected the upsurge of the addiction issue. Namely, it is estimated that the occurrence of the gaming issue among the adult population ranges from I\% to $1.5 \%$, and it can be argued that in Croatia there are at least 50,000 people addicted to gaming. The figures are very alarming (PBSVI, 2OI9). We should expect that the expansion of the market, especially online gambling, would make the problem of gambling addiction even more serious. It is obvious that the current regulations are not sufficient and require adjustments not only in the part concerning the taxation, but also in the part concerning the working hours of operators of the land-based gambling games. Furthermore, the operators should be obliged to inform the players on risks of online and land-based gaming and betting.

Therefore, the operators and their associations (Croatian Association for Games of Chance and Croatian Gaming Association) need to be more actively involved in the prevention. In this segment of economy the corporate social responsibility is a crucial requirement, and raising of the awareness and sensitivity of the society with regard to the issue of gambling addiction should not only be the concern of the government as the regulator.

The potential development of the market should not be observed only from the perspective of the current market model. The restrictions that arise from the previous suggestion to introduce more strict regulation may be compensated in other areas. In other words, Croatia is a tourismoriented country, and activities such as casinos and slog machine clubs are closely related with tourism and hotels all over the world. The other models aiming at enriching the tourist offer by means of gambling products and services should be taken into consideration. Such models would generate a new, so far non-existent, revenue from a large number of tourists visiting or just travelling through Croatia.

\section{Conclusion}

The gambling industry makes a smaller, but rather dynamic segment of the Croatian economy. The analysis of the gambling segment mostly covers the period 2OIO -2OI7. After the financial crisis in 20IO, the gambling market recorded growth and recovery. Besides the change of the regulations in 20I4, the development of digitalisation has highly influenced the market growth, especially in the segment of online gambling.

Furthermore, the market segment is not only profitable, but also highly concentrated and this high level of concentration is partially a result of acquisitions and entering of the foreign capital. In Croatia, the revenue form gambling grew despite the reduced number of companies and employed in the observed period. In 2OI7, the total revenue of this activity exceeded HRK 3 billion. The four main operators make more than $60 \%$ of the market. They are: Super Sport, HL, Interigre and Hattrick-PSK. Considering the market concentration, each of these companies is the market leader in a specific segment of the gambling sector.

The gambling sector comprises the following segments: lottery games, casinos, slot machine clubs and betting shops. In the segment of lottery, HL has monopoly and in the past couple of years the company has recorded growth in other segments as well. However, from the perspective of the revenue growth, labour productivity and profitability, HL is still lagging behind.

The betting shops have contributed to profitability and revenue growth of the gambling sector to a large extent. There are only six companies in the Republic of Croatia with the betting 
licence, and the top two are Super Sport and Hattrick-PSK. The operators that are primarily focused on betting also enter other market segments, primarily the segment of online casinos, which secures them the average annual revenue growth rate of $8 \%$.

The slot machine clubs have the average annual growth rate of $\mathrm{I} 2 \%$, which is double the average annual growth rate of the overall gambling and betting sector (6\%). This segment also recorded the highest number of mergers. The casinos have similar business trends as the slot machine clubs, since these are complementary market segment sharing the same key participants.

The gambling market in Croatia has been experiencing a significant growth. The regulations have been relatively slow adjusting to such growth as well as to the issues that arise from the gambling market development, especially in the sense of prevention of addiction and strengthening of the corporate social responsibility of the operators. The fees paid by the operators and taxes on winnings from gambling paid by players are the main regulatory instruments. Thus, in this area there is still space for the reallocation of the burden from the players to operators. Further market growth and development is still expected, especially on the grounds of development of online gambling, but also the improved EU regulation.

\section{References}

I. Act on Games of Chance, OG 87/o9, 35/I3, I58/I3, 4I/I4, I43/I4.

2. Anić, I. D. and Vouk, R., 200o. Comparison of Regulation of Gambling in the Republic of Croatia and EU Countries. Hrvatska gospodarska revija (Croatian Economic Journal), 9, I-IO

3. Bodor, D. and associates, 20I8. Prevalence of pathological prenatal gambling among alcohol addicts in outpatient treatment in the City of Zagreb: A cross-sectional study. Psychiatria Danubina, 30(3), 348-355

4. Decision on Granting the Authorisation to Organise Gambling in Casinos, OG II6/I8

5. Decision on Granting the Authorisation to Organise Gambling, OG II6/I8

6. Decision on Granting the Authorisation to Organise Slot Machine Gambling, OG II6/I8

7. EGBA, 20I7. Interactive map - Illegal gambling. European Gaming and Betting Association.

8. EGBA, 20I8. European Online Gambling - Key Figures 20I7. European Gaming and Betting Association.

9. European Commission, 2019. Data on taxation, National tax lists.

IO. FINA, 20I9. Public Disclosure of Financial Statements of All Companies in the Republic of Croatia. Zagreb: Financial Agency

II. General Tax Act, OG II5/I6, IO6/I8.

I2. Horak, H., Dumančić, K. and Pošćić, A., 20I7. Regulation of Gambling in the European Union. Zagreb: Školska knjiga.

13. Hrvatska Lutrija, 2013. Business and Development Plan of HL for a Three-year Period, 20I3 -20I5 Zagreb: HL.

I4. Ordinance on Interactive Online Casino Gaming, OG 78/IO.

I5. Ordinance on Lottery Games, OG 78/IO, 69/II, 22/I5, 45/I6, IOI/I8.

I6. Ordinance on Mandatory Records for the Calculation of the Fee Collected from the Operators, OG $8 / 15$.

17. Ordinance on Obtaining the Authorisation (Licence) to Work at a Casino, OG 78/10.

18. Ordinance on Organising Prize Winning Games, OG 8/IO.

I9. Ordinance on Organising Remote Betting, OG 8/IO, 63/IO, 22/I5. 
20. Ordinance on Spatial and Technical Requirements for Organisation of Gambling at Slot Machine Clubs, in Casinos and Betting Shops, OG 38/IO, I3O/IO, 69/II, I5/I2, I5I/I4.

2I. Ordinance on the Implementation of the General Tax Act, OG 45/I9.

22. Ordinance on the Technical Worthiness of Slot Machines and Gaming Tables, OG 38/IO, I3O/IO, 49/I3, I2/I4 .

23. Psihijatrijska bolnica Sv. Ivan (St. John Psychiatric Clinic), 2019. Gaming - Therapy and Rehabilitation Programm for Gaming Addiction. Zagreb: Psihijatrijska bolnica Sv. Ivan Zagreb (St. John Psychiatric Clinic).

24. Torre, R., Zoričić, Z. and Škifić, B., 20Io. Gaming Incidence and Legislation Medica Jadretina, 4O(I-2), 27-3I.

25. Zoričić, Z., Torre, R. and Orešković, A., 2009. Gaming and Betting - A New Age Addiction Medicus, $\mathrm{I} 7(2), 205-209$. 



\section{Fiscus}

Fiscus is an analytical serial publication of the Institute of Public Finance. It aims at analyzing current economic issues that affect the stability of public finances or are related to the production of goods and the provision of services of broader public interest. The topics concerned have not received adequate attention in the academic and professional community and relate to economic sectors in which the public interest is concerned, directly or indirectly. On scientific and professsional foundations, Fiscus seeks to empower and encourage public debate on the establishment and preservation of the stability of Croatian public finances and the economy in general by promoting transparent, prudent and responsible management. Therefore, the topics focus on the identification and quantification of potential risks that could threaten the stability of public finance, market development, the competitiveness of the Groatian economy and the economic position of the citizens.

The vision of Fiscus is to become a reliable source of sectoral analyses through the prism of interaction between the public and private sector.

The mission of Fiscus is to identify the key challenges faced by certain economic sectors and offer suggestions for the improvement and preservation of the long-term stability of the Croatian economy.

The main objectives are:

- to provide in-depth analysis of the financial operations of public sector institutions and those institutions that are in any way associated with the production of goods and the provision of services of a broader public interest;

- to improve understanding of the financial consequences of their operations and increase accountability;

- to provide objective information on their business operations to the broader professional public and to investors;

- to contribute to the removal of administrative barriers to the development of competetiveness and the market economy.

Publisher: Institute of Public Finance Zagreb, Smičiklasova 2I

Phone: (+385 I) 4886444 | fiscus@ijf.hr Editors: Anto Bajo and Marko Primorac www.ijf.hr/eng/fiscus 